\title{
Comparative phytochemistry of flavaglines (= rocaglamides), a group of highly bioactive flavolignans from Aglaia species (Meliaceae)
}

\author{
Harald Greger [
}

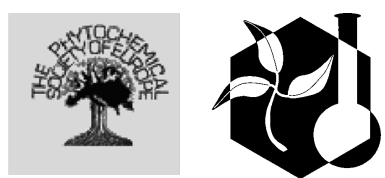

Received: 12 February 2021 / Accepted: 17 May 2021 / Published online: 4 June 2021

(C) The Author(s) 2021

\begin{abstract}
Flavaglines are formed by cycloaddition of a flavonoid nucleus with a cinnamic acid moiety representing a typical chemical character of the genus Aglaia of the family Meliaceae. Based on biosynthetic considerations 148 derivatives are grouped together into three skeletal types representing 77 cyclopenta[b]benzofurans, 61 cyclopenta[bc]benzopyrans, and 10 benzo[b]oxepines. Apart from different hydroxy, methoxy, and methylenedioxy groups of the aromatic rings, important structural variation is created by different substitutions and stereochemistries of the central cyclopentane ring. Putrescine-derived bisamides constitute important building blocks occurring as cyclic 2-aminopyrrolidines or in an open-chained form, and are involved in the formation of pyrimidinone flavaglines. Regarding the central role of cinnamic acid in the formation of the basic skeleton, rocagloic acid represents a biosynthetic precursor from which aglafoline- and rocaglamidetype cyclopentabenzofurans can be derived, while those of the rocaglaol-type are the result of decarboxylation. Broad-based comparison revealed characteristic substitution trends which contribute as chemical markers to natural delimitation and grouping of taxonomically problematic Aglaia species. A wide
\end{abstract}

H. Greger $(\bowtie)$

Chemodiversity Research Group, Faculty of Life

Sciences, University of Vienna, Rennweg 14, 1030 Wien,

Austria

e-mail: harald.greger@univie.ac.at variety of biological activities ranges from insecticidal, antifungal, antiprotozoal, and anti-inflammatory properties, especially to pronounced anticancer and antiviral activities. The high insecticidal activity of flavaglines is comparable with that of the well-known natural insecticide azadirachtin. Comparative feeding experiments informed about structure-activity relationships and exhibited different substitutions of the cyclopentane ring essential for insecticidal activity. Parallel studies on the antiproliferative activity of flavaglines in various tumor cell lines revealed similar structural prerequisites that let expect corresponding molecular mechanisms. An important structural modification with very high cytotoxic potency was found in the benzofuran silvestrol characterized by an unusual dioxanyloxy subunit. It possessed comparable cytotoxicity to that of the natural anticancer compounds paclitaxel (Taxol®) and camptothecin without effecting normal cells. The primary effect was the inhibition of protein synthesis by binding to the translation initiation factor eIF4A, an ATP-dependent DEAD-box RNA helicase. Flavaglines were also shown to bind to prohibitins (PHB) responsible for regulation of important signaling pathways, and to inhibit the transcriptional factor HSF1 deeply involved in metabolic programming, survival, and proliferation of cancer cells. Flavaglines were shown to be not only promising anticancer agents but gained now also high expectations as agents against emerging RNA viruses like SARS-CoV-2. Targeting the 
helicase eIF4A with flavaglines was recently described as pan-viral strategy for minimizing the impact of future RNA virus pandemics.

Keywords Aglaia Meliaceae - Flavaglines ·

Rocaglamides · Rocaglates · Cyclopentabenzofurans · Cyclopentabenzopyrans - Benzoxepines $\cdot$ Structural relationships · Chemotaxonomy $\cdot$ Biological activities · Translational repression - Insecticidal · Antiprotozoal · Antifungal · Anticancer · Antiviral · Anti-inflammatory

\section{Introduction}

In the course of our broad-based bioassay-guided screening for naturally occurring insecticides and fungicides in tropical rainforests we found exceptionally high insecticidal activities in some Aglaia species of the family Meliaceae. In accordance with previous findings (Satasook et al. 1992; Janprasert et al. 1993; Ishibashi et al. 1993; Ewete et al. 1996; Nugroho et al. 1997a, b; Güssregen et al. 1997) the activities could be attributed to a group of cyclopenta[b]benzofurans (Brader et al. 1998; Bacher et al. 1999). Some derivatives were shown to have also antifungal properties, displaying high activity particularly against Pyricularia grisea, the causative fungus of rice blast disease (Engelmeier et al. 2000). Continuative studies, especially by Proksch and collaborators, revealed further insecticidal derivatives which all were characterized by a benzofuran basic skeleton (Hiort et al. 1999; Chaidir et al. 1999, 2001; Molleyres et al. 1999; Nugroho et al. 1999; Schneider et al. 2000; Dreyer et al. 2001; Greger et al. 2001; Bringmann et al. 2003; Koul et al. 2004, 2005; Duong 2005; Hall et al. 2017).

The formation of cyclopenta[ $b]$ benzofurans was shown to represent a characteristic chemical feature of the genus Aglaia not detected so far in any other genus of the Meliaceae. The first derivative of this group, rocaglamide (25), exhibited significant antileukemic activity and was isolated from Aglaia rimosa (Blanco) Merrill (= A. elliptifolia Merrill) collected in Taiwan (King et al. 1982). As a consequence, apart from ongoing screenings for insecticidal properties, there has also been a great parallel interest in that class of compounds as potential anticancer agents (Ohse et al.
1996; Wu et al. 1997; Cui et al. 1997; Lee et al. 1998; Bohnenstengel et al. 1999a,b; Wang and Duh 2001; Hausott et al. 2004; Mi et al. 2006a; Zhu et al. 2007, 2009; Cencic et al. 2009; Ribeiro et al. 2012; Basmadjian et al. 2013). Moreover, anti-inflammatory (Baumann et al. 2002; Proksch et al. 2005; Fahrig et al. 2005; Salim et al. 2007b), antiprotozoal (Phongmaykin et al. 2011; Astelbauer et al. 2011, 2012; Langlais et al. 2018; Drinić et al. 2019), and more recently, antiviral activities (Biedenkopf et al. 2017; Müller et al. 2018, 2020, 2021; Todt et al. 2018; Glitscher et al. 2018; Elgner et al. 2018; Henss et al. 2018; Schulz et al. 2021; Taroncher-Oldenburg et al. 2021) were also reported which greatly stimulated further research in this class of compounds.

The discovery of structurally related derivatives with a cyclopenta[$[b c]$ benzopyran skeleton in the leaves of $A$. argentea Blume and benzo[b]oxepines in the bark of $A$. forbesii King, coexisting with flavonoids and bisamides, suggested a common biogenetic origin (Dumontet et al. 1996). In two subsequent reports a biosynthetic pathway was proposed independently, suggesting the formation of a flavolignan basic skeleton created by cycloaddition between a flavonoid nucleus and a cinnamic acid moiety (Bacher et al. 1999; Nugroho et al. 1999). For the sake of convenience the benzofuran derivatives were previously designated as rocaglamides following the trivial name of the first derivative (Proksch et al. 2001). However, the benzofurans isolated from other Aglaia species, e.g. from A. elliptica Blume (Lee et al. 1998), A. elaeagnoidea (A. Juss.) Benth. (Brader et al. 1998) or A. spectabilis (Miq.) Jain \& Bennet (Schneider et al. 2000), were shown to be devoid of nitrogen. Hence, the name rocaglamides as general denomination for this class of compounds appeared to be not appropriate and, instead, we have proposed their designation as flavaglines, regarding their restricted occurrence in the genus Aglaia and the incorporation of a flavonoid moiety as a central building block (Brader et al. 1998).

On the basis of our broad-based UV-HPLC comparison of 30 different Aglaia species ${ }^{1}$ it became apparent that benzofuran flavaglines are mainly accumulated in the stem bark and roots, while benzopyran flavaglines are dominating in the leaves, coexisting with bisamides, lignans, and flavonoids (Brem 2002).

\footnotetext{
1 A list of corresponding voucher specimens and GenBank accession numbers is presented in Muellner et al. (2009)
} 
However, in some species no flavaglines could be detected in this preliminary survey, where only small quantities of plant material were used. In this case, mostly bisamides and/or lignans were shown to be the dominating compounds in the UV-HPLC-profiles, sometimes accumulated in all three plant parts, the leaves, stem bark, and roots (Greger et al. 2000, 2008; Bachratá 2008). The ecological impact of flavagline formation became apparent in parallel bioassays of crude extracts against the polyphagous pest insect Spodoptera littoralis, where pronouced insect toxicity was observed only in those species which showed an accumulation of benzofuran flavaglines (Greger et al. 2000, 2001, 2008; Brem 2002). Investigations within the distribution area of Aglaia, ranging from Sri Lanka to Fiji islands, did not show significant differences in the biogenetic capacity towards flavagline formation between species of the western part to those of the eastern part, across the Wallace's line (Greger et al. 2001; Muellner et al. 2005, 2009).

Regarding the results available so far flavaglines are unlikely to be developed into a commercial insecticide (Ebada et al. 2011; Hall et al. 2017), but their remarkable activity against cancer cell lines at nanomolar concentrations makes them extremly attractive as therapeutic agent candidates in cancer chemotherapy, even more, as they did not display major toxicity on normal cells (Hausott et al. 2004; Su et al. 2006; Zhu et al. 2007; Ribeiro et al. 2012; Pan et al. 2013; Callahan et al. 2014; Emhemmed et al. 2019). The primary effect of their antiproliferative activity was reported to be due to inhibition of protein synthesis (Ohse et al. 1996; Lee et al. 1998). It is now known that this effect is due to the binding of flavaglines to the translation initiation factor eIF4A, an ATP-dependent DEAD-box RNA helicase (Bordeleau et al. 2008; Cencic et al. 2009; Sadlish et al. 2013). Targeting the prohibitins- 1 and 2 , two evolutionarily conserved and ubiquitously expressed proteins controlling important cellular processes, was also discussed (Polier et al. 2012; Thuaud et al. 2013; Basmadjian et al. 2013, 2015). Further molecular mechanisms were summarized by Li-Weber (2015). The discovery of the exceptionally high activities of silvestrol (14), a benzofuran flavagline linked with an unusual 1,4-dioxanyloxy or "pseudosugar" substituent (Hwang et al. 2004), has greatly accelerated further pharmacological investigations, principally for the treatment of cancer (Kim et al. 2006b; Lucas et al.
2009; Aktas et al. 2011; Basmadjian et al. 2013; Pan et al. 2014; Patton et al. 2014; Chen et al. 2016). These outstanding activities together with the intriguing chemical structures of flavaglines, characterized by a densely functionalized tricyclic nucleus with five contiguous stereocenters, attracted considerable synthetic interest. Starting with the first total synthesis of rocaglamide (25) (Trost et al. 1990), Zhao et al. (2016) provided an overview about the various synthetic approaches to the total synthesis of flavaglines.

Apart from the successful development of synthetic analogues with high antiproliferative properties (Gerard et al. 2004; Thede et al. 2004; Adams et al. 2009; Thuaud et al. 2009, 2011; Roche et al. 2010; Rodrigo et al. 2012; Liu et al. 2012; Lajkiewicz et al. 2012; Hawkins et al. 2014; Chu et al. 2019; Maïga et al. 2019; Chan et al. 2019; Harmouch et al. 2020; Yan et al. 2020; Ernst et al. 2020), further studies on structural diversification and distribution of naturally occurring flavaglines are greatly hampered by taxonomic problems especially in the complex species in Aglaia (Pannell 1992). As a consequence, published reports on flavaglines are frequently attributed to the wrong species and have resulted in confusion in the chemical and pharmaceutical literature. This makes it difficult to compare the results of the different research groups, to replicate their work or to use the data for chemotaxonomic conclusions. Relying on expert identification by Caroline Pannell from the University of Oxford broad-based phytochemical comparisons in our laboratory exhibited characteristic biogenetic trends which already contributed as chemical markers together with morphological characters and DNA sequence data to a more natural taxonomic grouping (Brem 2002; Muellner et al. 2005, 2009). The present review provides a visual reference guide to the structural diversity of naturally occurring flavaglines, including all newly described derivatives. On the basis of biosynthetic considerations and the coexistence of characteristic substitution patterns 148 flavaglines were grouped into 77 benzofurans, 61 benzopyrans, and 10 benzoxepins. Different accumulation trends and structural variation were compared with regard to the presently suggested species delimitation and grouping in Aglaia. In addition, the purpose of this article is to give an updated summary of the numerous publications demonstrating the wide range of bioactivities of this fascinating class of compounds. 


\section{Structural relationships}

Although the biosynthesis of flavaglines is not yet confirmed experimentally, the biogenetic correlations of three basic skeletons shown in Fig. 1 are widely accepted. According to that a flavonoid nucleus is linked to a cinnamic acid moiety resulting in the formation of a cyclopenta[bc]benzopyran skeleton which represents a biosynthetic key intermediate to both the cyclopenta[$[b]$ benzofurans and benzo $[b]$ oxepines (Bacher et al. 1999; Nugroho et al. 1999; Kim et al. 2006b). This hypothesis is supported by the occurrence of common substitution patterns of the aromatic rings $\mathrm{A}$ and $\mathrm{B}$ in all three skeletal types and in the co-occurring flavonoids (Brem 2002). The formation of the benzofuran skeleton can be explained by opening the 5-5a bond of the benzopyran precursor and closing the $5 \mathrm{a}-10$ bond, whereas the benzoxepines may be derived from the benzopyrans by a cleavage of the 10-5 bond (Fig. 1). The stereochemical implications created by these conversions were discussed by Bacher et al. (1999) and Proksch et al. (2001).
Bisamides

The occurrence of flavaglines was shown to be closely correlated with the formation of putrescine-derived bisamides representing both characteristic constituents of the leaf extracts of Aglaia species as well as important building blocks of many flavaglines (Fig. 2). Structurally, bisamides were found to occur either as cyclic 2-aminopyrrolidine derivatives (Table 1A) or in an open-chained form (Table 1B). The former were shown to have a more restricted distribution so far only known from the genus Aglaia (Detterbeck and Hesse 2002). Besides a few derivatives containing two identical acid moieties the majority of bisamides is characterized by two different acid residues with cinnamic acid as the most frequent acid part. Following the supposed biogenetic correlations outlined in Fig. 1, it represents the structural prerequisit for the incorporation of bisamides into flavaglines. As shown in Table 1A and B the cinnamic acid-derived bisamides are frequently linked with 2-methyl butyric acid as second acid part which shows further variation by different hydroxylations, dehydrations (tiglic acid), and stereochemistry (Hayashi et al. 1982; Duh et al. 1993; Saifah et al. 1993; Duong
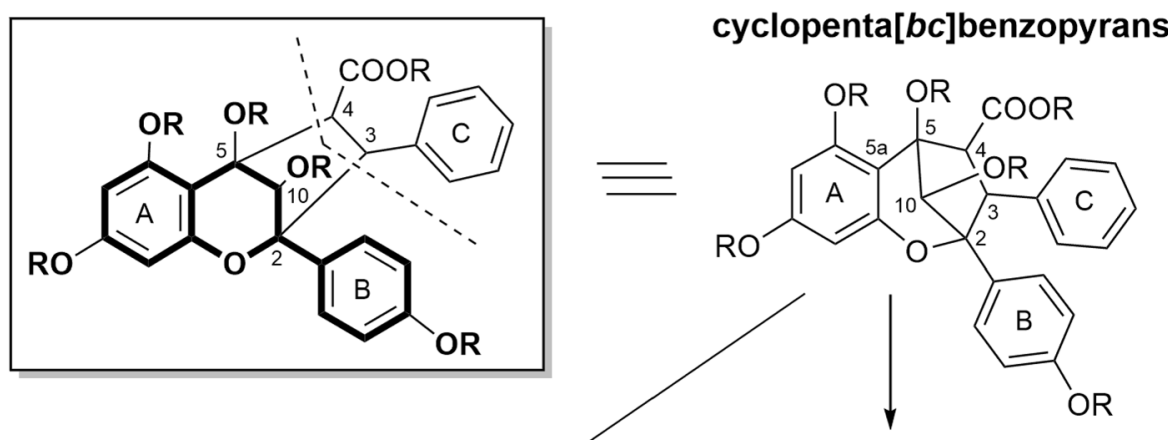

cyclopenta[b]benzofurans

\section{benzo[b]oxepines}
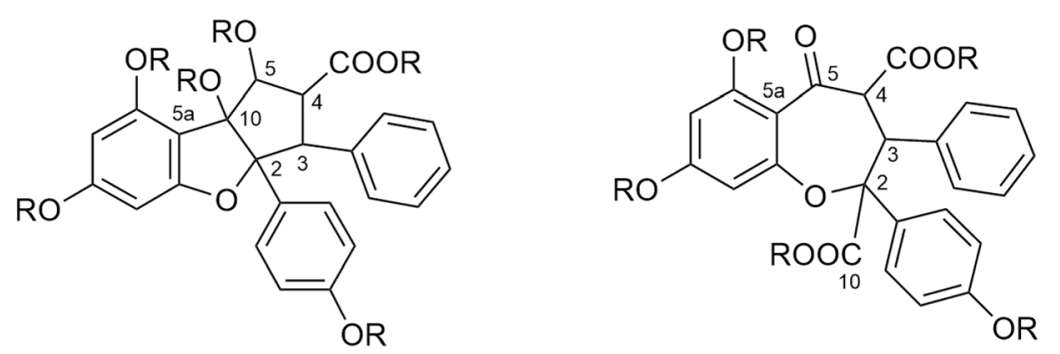

Fig. 1 Proposed biogenetic correlation between flavagline skeletons (note the numbering of the benzopyran ring is used here for all structures) (Bacher et al. 1999) 
et al. 2007). In addition, isobutyric, isovaleric, senecioic, phenylacetic, and benzoic acid moieties were also reported. In A. leucophylla King, published as A. leptantha Miq. (Greger et al. 2000), and A. edulis (Roxb.) Wall. (Saifah et al. 1999; Kim et al. 2006a) bisamides were shown to be also linked to the rare methylthiopropenoic acid. However, to date no sulfurcontaining bisamides have been reported as part of flavaglines. The threefold acylated putrescine derivative edulimide was isolated as a major component from the leaf extract of A. edulis collected in SEThailand. In addition to cinnamic and dihydrocinnamic acid edulimide contains an acetic acid moiety forming an imide group (Brader et al. 1998) (Table 1B). The discovery of structurally corresponding amide esters in A. tenuifolia Hiern let expect close biogenetic connections to bisamides. In this case one nitrogen atom has obviously been replaced with oxygen (Greger et al. 2008).

Based on the flavagline structures reported so far it became evident that putrescine-derived bisamides are essential building blocks mainly incorporated into benzopyran and benzoxepine derivatives. In this case both open-chained and cyclic bisamides are inserted as a whole maitaining their overall structure and substitution pattern. This became especially clear e.g. with the formation of aglain A (84) and aglaforbesin A (97), where odorine is incorporated in two different positions (Fig. 2).

\section{Benzofuran flavaglines}

As shown in Tables 2, 3, and 4, putrescine-derived bisamides are mostly linked to benzopyran and benzoxepine flavaglines, but were also detected in the unnamed benzofuran 64 (Dreyer et al. 2001). A hypothetical putrescine-derived aminopyrrolidine amide was suggested to form a series of pyrimidinones (65-74). In this case the pyrimidinone moiety was speculated to be created by a condensation reaction between the $\mathrm{NH}_{2}$-group of the amide with the $\mathrm{OH}$ group at $C$ - 1 of the benzofuran moiety (Fig. 3) (Greger et al. 2008). From ten pyrimidinones listed in Table 2 the three derivatives aglaiastatin (65) (Ohse et al. 1996), aglaroxin I (71), and aglaroxin H (73) (Molleyres et al. 1999) deviate by a reduced bond between
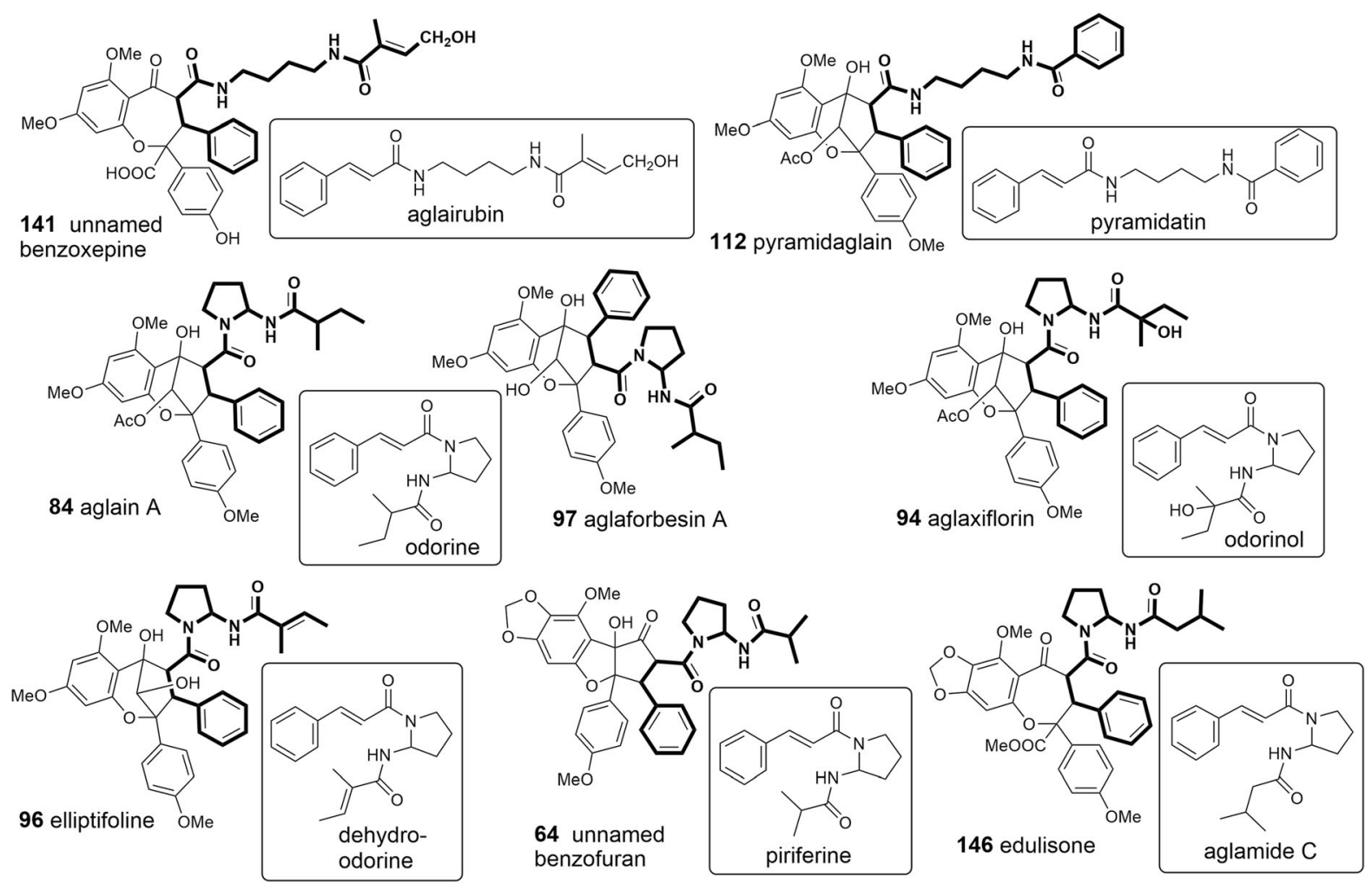

Fig. 2 Various bisamides as building blocks of flavaglines (Greger et al. 2008) 
Table 1 Putrescine-derived bisamides from Aglaia species

\section{A Cyclic derivatives}<smiles>CCC(C)C(=O)NC1CCCN1C(=O)/C=C/c1ccccc1</smiles>

odorine

Shiengthong et al. 1979

$=$ roxburghilin

Purushothaman et al. 1979<smiles>CC(C)C(=O)NC1CCCN1C(=O)/C=C/c1ccccc1</smiles>

piriferine

Saifah et al. 1988<smiles>C[AsH3]O[AsH3]</smiles>

Kim et al. 2006a<smiles>CCC(C)(O)C(=O)NC1CCCN1C(=O)/C=C/c1ccccc1</smiles>

odorinol Shiengthong et al. 1979<smiles>C/C=C(\C)C(=O)NC1CCCN1C(=O)/C=C/c1ccccc1</smiles>

dehydroodorine Duh et al. 1993<smiles>CC=C(C)C(=O)NC(CCCO)NC(=O)C=Cc1ccccc1</smiles>

elliptinol

Wang et al. 2001b<smiles>CC(C)CC(=O)NC1CCCN1C(=O)/C=C/c1ccccc1</smiles>

aglamide $\mathrm{C}$

Kim et al. 2006a<smiles>CSC=CC(=O)NC1CCCN1C(=O)C=Cc1ccccc1</smiles>

aglamide $\mathrm{A}$

Kim et al. 2006a<smiles>C/C=C/C(=O)N1CCCC1NC(=O)/C=C/c1ccccc1</smiles>

agleptin

Greger et al. 2000<smiles>CS(=O)(=O)/C=C/C(=O)NC1CCCN1C(=O)Cc1ccccc1</smiles>

isoagleptin

Greger et al. 2000<smiles>CS/C=C/C(=O)NC1CCCN1C(=O)/C=C/SC(C)(C)C</smiles>

leptanthin

Greger et al. 2000<smiles>COC1CCCN1C(=O)/C=C/c1ccccc1</smiles>

aglamide $\mathrm{D}$

Kim et al. 2006a 
Table 1 continued

\section{B Open-chained derivatives}<smiles>CC(C)C(=O)NCCCCNC(=O)/C=C/c1ccccc1</smiles><smiles>CCC(C)C(=O)NCCCCNC(=O)/C=C/c1ccccc1</smiles><smiles>CC=C(C)C(=O)NCCCCNC(=O)C=Cc1ccccc1</smiles>
Inada et al. 2000<smiles>C/C(=C\CO)C(=O)NCCCCNC(=O)/C=C/c1ccccc1</smiles><smiles>C=C(C(=O)NCCCCNC(=O)/C=C/c1ccccc1)C(C)O</smiles><smiles>CC1=C[C@@H](O)N(CCCCNC(=O)/C=C/c2ccccc2)C1=O</smiles><smiles>CS/C=C/C(=O)NCCCCNC(=O)Cc1ccccc1</smiles>
aglaithioduline Saifah et al. 1999 (= leptaglin, Greger et al. 2000)<smiles>O=C(/C=C/c1ccccc1)NCCCCNC(=O)c1ccccc1</smiles><smiles>C=C(C(=O)NCCCCNC(=O)/C=C/c1ccccc1)C(O)CO</smiles><smiles>CS/C=C/C(=O)NCCCCNC(=O)/C=C/c1ccccc1</smiles><smiles>CC=CC(=O)NCCCCNC(=O)C=CSC</smiles>

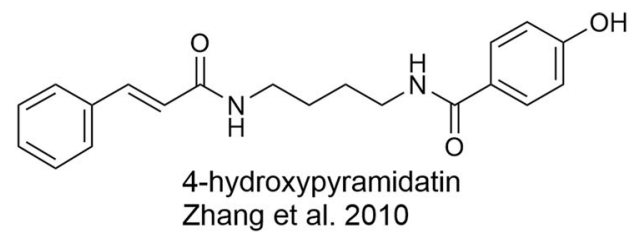<smiles>O=C(/C=C/c1ccccc1)NCCCCNC(=O)Cc1ccc(O)cc1</smiles>

unnamed

Chin et al. 2010

(= aglaianine, Zhang et al. 2011)<smiles>O=C(Cc1ccccc1)NCCCCNC(=O)Cc1ccccc1</smiles>

(= aglanthin, Greger et al. 2000)<smiles>CC(=O)N(CCCCNC(=O)/C=C/c1ccccc1)C(=O)CCc1ccccc1</smiles> 
Table 2 Benzofuran flavaglines

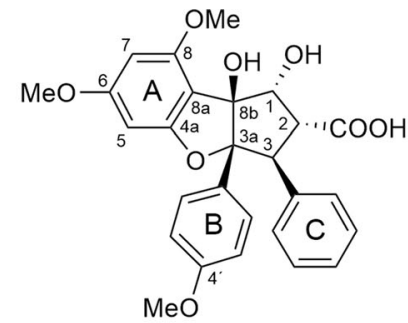

1 rocagloic acid Wang et al. 2001<smiles>COc1ccc([C@]23Oc4cc(OC)cc(OC)c4[C@@]2(O)[C@@H](C=O)[C@@H](C(=O)O)[C@H]3c2ccccc2)cc1</smiles>

2 1-O-formyl-rocagloic acid Chumkaew et al. 2006<smiles>COc1cc(OC)c2c(c1)O[C@@]1(c3ccc(OC)c(O)c3)[C@H](c3ccccc3)[C@@H](C(=O)O)[C@H](O)[C@@]21O</smiles>

3 3'-hydroxy-rocagloic acid Chumkaew et al. 2006

\section{Aglafoline-type}<smiles>COc1ccc([C@]2(c3ccccc3)Oc3cc(OC)cc(OC)c3[C@@]2(O)[C@H](O)[C@H](OC)C(C)=O)cc1</smiles>

4 aglafoline Ko et al. 1992 (= methyl rocaglate Ishibashi et al. 1993)<smiles>COC(=O)[C@@H]1C[C@]2(O)Oc3c(OC)cc(OC)cc3O[C@@]1(c1ccc(OC)c(O)c1)[C@@H]2c1ccccc1</smiles>

7 3'-hydroxyaglafoline Nugroho et al. 1999

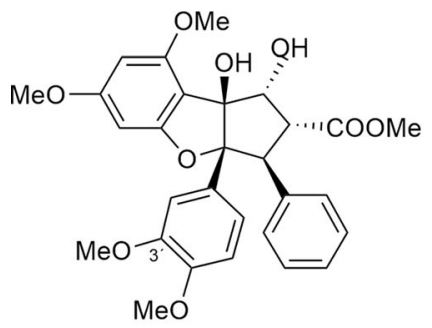

10 3'-methoxyaglafoline Schneider et al. 2000<smiles>COC[C@@H](C(C)=O)[C@@H](OC=O)[C@]1(O)c2c(OC)cc(OC)cc2O[C@@]1(c1ccccc1)c1ccc(OC)cc1</smiles>

\section{1-O-formylaglafoline} Schneider et al.2000<smiles>COc1cc(OC)c2c(c1)O[C@@]1(c3ccc(OC)c(O)c3)[C@H](c3ccccc3)[C@@H](C(=O)OC=O)[C@]2(O)[C@H]1O</smiles>

8 1-O-formyl-3'-hydroxyaglafoline

Schneider et al. 2000<smiles>COc1ccc([C@]23Oc4cc(OC)cc(OC)c4[C@@]2(C)[C@@H](O)[C@H](C(C)=O)[C@H]3c2ccccc2)cc1</smiles>

11 8b-methoxyaglafoline Hiort et al. 1999<smiles>COC(=O)[C@@H]1[C@H](OC(C)=O)[C@@]2(O)c3c(OC)cc(OC)cc3O[C@]2(c2ccc(OC)cc2)[C@@H]1c1ccccc1</smiles>

6 1-O-acetylaglafoline Chaidir et al. 1999<smiles>COc1cc(OC)c2c(c1)O[C@@]1(c3ccc(OC)c(O)c3)[C@H](c3ccccc3)[C@@H](C(C)=O)[C@H](OC(C)=O)[C@]21O</smiles>

9 1-O-acetyl-3'-hydroxyaglafoline Güssregen et al. 1997<smiles>COC1=CC=C([C@]2(c3ccccc3)Oc3cc(OC)cc(OC)c3[C@@]2(O)/C(=N/O)[C@@H](OC)C(C)=O)[C@H]1c1ccc(OC)cc1</smiles>

12 rocaglamide $A Y$ Duong et al. 2014 
Table 2 continued<smiles>COc1cc(OC)c2c(c1)O[C@]1(c3ccc(OC)c(OC)c3)[C@H](c3ccccc3)[C@@H](C(C)=O)/C(=N\O)[C@@]21O</smiles>

13 unnamed oxime Nugroho et al. 1999

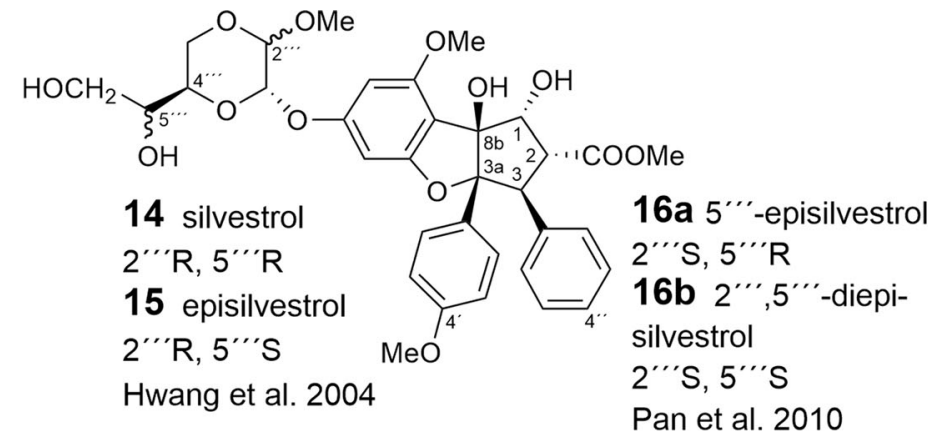

Pan et al. 2010

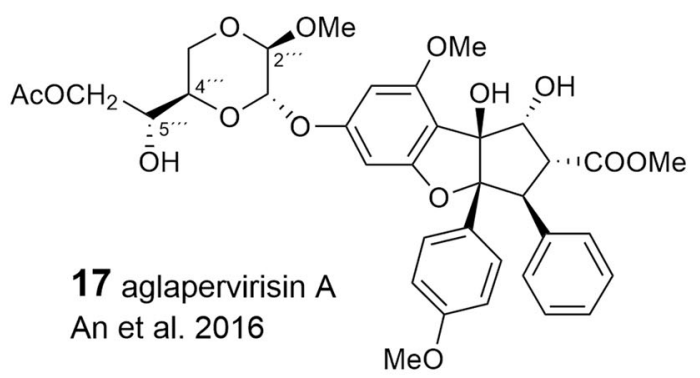<smiles>COc1cc(OC)c2c(c1)O[C@]1(c3ccc4c(c3)OCO4)[C@H](c3ccccc3)[C@@H](C(C)=O)[C@H](O)[C@]21O</smiles>

$184^{\prime}$-demethoxy-3',4'methylenedioxyaglafoline Cui et al. 1997<smiles>COc1cc(OC)c2c(c1)O[C@]1(c3ccc4c(c3)OCO4)[C@H](c3ccccc3)[C@@H](C(=O)OC=O)[C@]21O</smiles>

19 1-O-formyl-4'-demethoxy3',4'-methylenedioxyaglafoline Cui et al. 1997<smiles></smiles>

22 pannellin Brader et al. 1998

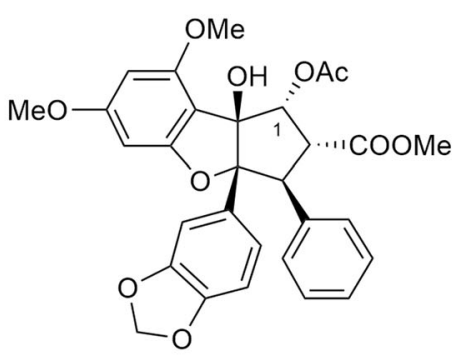

20 1-O-acetyl-4'-demethoxy$3^{\prime}, 4^{\prime}$-methylenedioxyaglafoline Schneider et al. 2000<smiles></smiles>

23 1-O-acetylpannellin Brader et al. 1998<smiles>COc1cc(OC)c2c(c1)O[C@@]1(c3ccc4c(c3)OCO4)[C@H](c3ccccc3)[C@@H](C(C)=O)[C@]21O</smiles>

21 8b-methoxy-4'-demethoxy$3^{\prime}, 4^{\prime}$-methylenedioxyaglafoline Pan et al. 2013<smiles></smiles>

24 3'-methoxypannellin Brader et al. 1998 
Table 2 continued

\section{Rocaglamide-type}<smiles>COc1ccc([C@]2(c3ccccc3)Oc3cc(OC)cc(OC)c3[C@@]2(O)[C@H](O)[C@H](C(=O)N(C)C)C(C)C)cc1</smiles>

25 rocaglamide King et al. 1982<smiles>COc1cc(OC)c2c(c1)O[C@@]1(c3ccc(OC)c(O)c3)[C@H](c3ccccc3)[C@@H](C(=O)N(C)C)[C@H](OC(C)=O)[C@]21O</smiles>

28 1-0-acetyl-3'-hydroxyrocaglamide

Nugroho et al. 1997a<smiles>COc1cc(OC)c2c(c1)O[C@@]1(c3ccc(OC)c(OC)c3)[C@H](c3ccccc3)[C@@H](C(=O)N(C)C)[C@H](O)[C@]21O</smiles>

31 aglaroxin $\mathrm{E}$ Nugroho et al. 1997a Molleyres et al. 1999<smiles>[CH]NC(=O)[C@H]1[C@@H](c2ccccc2)[C@@]2(c3ccc(OC)cc3)Oc3cc(OC)cc(OC)c3[C@@]2(OC)[C@@H]1O</smiles>

34 8b-methoxy-desmethylrocaglamide Liu et al. 2013<smiles>COc1ccc([C@]2(c3ccccc3)Oc3cc(OC)cc(OC)c3[C@@]2(O)[C@H](OC(C)=O)[C@@H](C(C)=O)C(=O)N(C)C)cc1</smiles>

26 1-O-acetylrocaglamide Hiort et al. 1999<smiles>COc1cc(OC)c2c(c1)O[C@@]1(c3ccc(OC)c(O)c3)[C@H](c3ccccc3)[C@@H](C(=O)N(C)C)[C@H](O)[C@@]21OC</smiles>

29 3'-hydroxy-8b-methoxyrocaglamide

Liu et al. 2013<smiles>[CH][Y1]([O-])([O-])NC(=O)[C@@H]1[C@@H](c2ccccc2)[C@@]2(c3ccc(OC)cc3)Oc3cc(OC)cc(OC)c3[C@@]2(O)[C@H]1O</smiles>

32 desmethylrocaglamide Ishibashi et al. 1993<smiles>CNN(C)C(=O)[C@H]1[C@H](O)[C@@]2(O)c3c(OC)cc(OC)cc3O[C@]2(c2ccc(OC)c(O)c2)[C@@H]1c1ccccc1</smiles>

35 3'-hydroxy-desmethylrocaglamide Nugroho et al. 1999<smiles>COc1cc(OC)c2c(c1)O[C@@]1(c3ccc(OC)c(O)c3)[C@H](c3ccccc3)[C@@H](C(=O)N(C)C)[C@H](O)[C@]21O</smiles>

27 3'-hydroxyrocaglamide Nugroho et al. 1997 a<smiles>CCO[C@@]12c3c(OC)cc(OC)cc3O[C@@]1(c1ccc(OC)c(O)c1)[C@H](c1ccccc1)[C@H](C(=O)N(C)C)[C@H]2O</smiles>

30 3'-hydroxy-8b-ethoxyrocaglamide

Chaidir et al. 1999<smiles>COc1ccc([C@]23Oc4cc(OC)cc(OC)c4[C@@]2(O)[C@@H](OC(C)=O)[C@@H](C(=O)N[Y1](C)(=O)=O)[C@H]3c2ccccc2)cc1</smiles>

33 1-O-acetyl-desmethylrocaglamide

Hiort et al. 1999<smiles>[CH]NC(=O)[C@@H]1[C@@H](c2ccccc2)[C@@]2(c3ccc(OC)c(O)c3)Oc3cc(OC)cc(OC)c3[C@@]2(O)[C@H]1OC(C)=O</smiles>

36 1-0-acetyl-3'-hydroxydesmethylrocaglamide Güssregen et al. 1997 
Table 2 continued<smiles>CCO[C@@]12c3c(OC)cc(OC)cc3O[C@@]1(c1ccc(OC)c(O)c1)[C@H](c1ccccc1)[C@H](C(=O)N(C)NC)[C@H]2O</smiles>

37 3'-hydroxy-8b-ethoxydesmethylrocaglamide Chaidir et al. 1999<smiles>COc1cc(OC)c2c(c1)O[C@@]1(c3ccc(OC)c(O)c3)[C@H](c3ccccc3)[C@@H](C(N)=O)[C@H](O)[C@@]21O</smiles>

40 3'-hydroxydidesmethylrocaglamide

Güssregen et al. 1997<smiles>COc1ccc([C@]23Oc4cc(OC)cc(OC)c4[C@@]2(O)[C@@H](O)[C@@H](C(N)=O)[C@H]3c2ccccc2)cc1</smiles>

38 didesmethylrocaglamide Dumontet et al. 1996<smiles>COc1ccc([C@]23Oc4cc(OC)cc(OC)c4[C@@]2(O)[C@H](OC(C)=O)[C@@H](C(N)=O)[C@@H]3c2ccccc2)cc1</smiles>

39 1-O-acetyldidesmethylrocaglamide

Chaidir et al. 1999

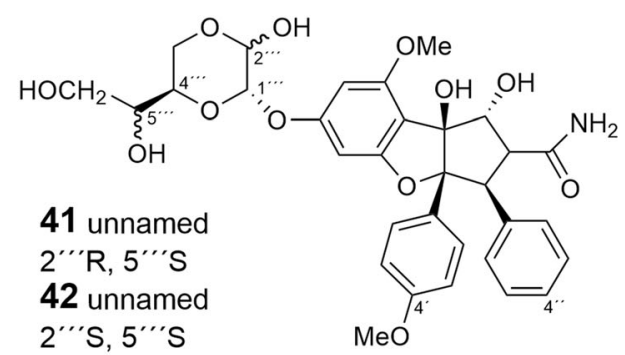
Agarwal et al. 2019<smiles></smiles>

47 aglaroxin $A$ Molleyres et al. 1999<smiles></smiles>

48 1-O-acetylaglaroxin A Kim et al. 2006a
Agarwal et al. 2019<smiles></smiles>

49 1-O-acetyl-8b-methoxydidesmethylaglaroxin $\mathrm{A}$ Hofer 2002<smiles>CCNC(=O)[C@@H]1[C@H](O)[C@]2(O)c3c(cc4c(c3OC)OCO4)O[C@]2(c2ccc(OC)c(OC)c2)[C@H]1c1ccccc1</smiles>

50 aglaroxin $B$ Molleyres et al. 1999<smiles>COc1ccc([C@]23Oc4cc5c(c(OC)c4[C@@]2(O)[C@@H](OC(C)=O)[C@@H](C(C)=O)[C@@H]3c2ccccc2)OCO5)cc1OC</smiles>

51 1-O-acetylaglaroxin $B$

Kim et al. 2006a (= 3'-methoxyaglaroxin A 1-Oacetate) 
Table 2 continued<smiles>COc1ccc([C@]23Oc4cc5c(c(OC)c4[C@@]2(O)[C@@H](O)[C@@H](C(C)=O)[C@@H]3c2ccccc2)OCO5)c(O)c1OC</smiles>

52 aglaroxin $\mathrm{F}$ Molleyres et al. 1999 Bringmann et al. 2003

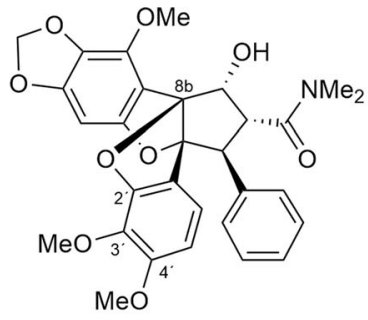

53 cyclorocaglamide Bringmann et al. 2003

\section{Rocaglaol-type}<smiles>COc1ccc([C@]23Oc4cc(OC)cc(OC)c4[C@@]2(O)[C@@H](O)C[C@H]3c2ccccc2)cc1</smiles>

54 rocaglaol Ishibashi et al. 1993<smiles>CCO[C@@]12c3c(OC)cc(OC)cc3O[C@@]1(c1ccc(OC)cc1)[C@H](O)C[C@H]2c1ccccc1</smiles>

57 8b-ethoxyrocaglaol Dumontet et al. 1996<smiles>COc1cc(OC)c2c(c1)O[C@@]1(c3ccc4c(c3)OCO4)[C@H](c3ccccc3)C[C@H](O)[C@]21O</smiles>

61 4'-demethoxy-3',4'methylenedioxyrocaglaol Cui et al.1997<smiles></smiles>

55 1-O-acetylrocaglaol Rivero-Cruz et al. 2004<smiles>COc1cc(OC)c2c(c1)O[C@@]1(c3ccc(OC)c(OC)c3)[C@@H](c3ccccc3)C[C@@H](O)[C@]21O</smiles>

58 3'-methoxyrocaglaol Güssregen et al. 1997<smiles>COc1cc(OC)c2c(c1)O[C@@]1(c3ccc4c(c3)OCO4)[C@H](c3ccccc3)C[C@H](O)[C@@]21OC</smiles>

62 8b-methoxy-4'-demethoxy3',4'-methylenedioxyrocaglaol Pan et al. 2013<smiles>COc1ccc([C@]23Oc4cc(OC)cc(OC)c4[C@@]2(OC)[C@@H](O)C[C@H]3c2ccccc2)cc1</smiles>

56 8b-methoxyrocaglaol Hiort et al. 1999

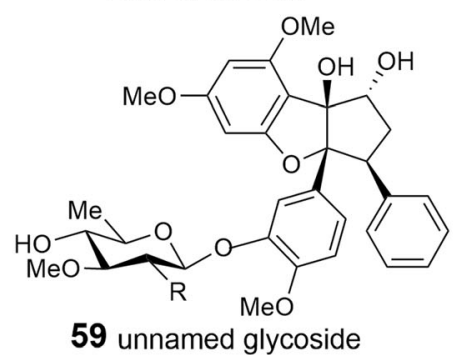

$\mathrm{R}=\mathrm{OH}$

Nugroho et al. 1997b

60 unnamed glycoside $\mathrm{R}=\mathrm{OAC}$

Xu et al. 2000<smiles>COc1cc(OC)c2c(c1)O[C@@]1(c3ccc4c(c3)OCO4)[C@@H](c3ccccc3)CC(=O)[C@@]21O</smiles>

63 1-oxo-4'-demethoxy-3',4'methylenedioxyrocaglaol

Cui et al.1997 
Table 2 continued

\section{Benzofurans with putrescine-derived amide moieties}<smiles>COc1ccc([C@]23Oc4cc5c(c(OC)c4[C@]2(O)C(=O)[C@H](C(=O)N2CCC[C@H]2NC(=O)C(C)C)[C@@H]3c2ccccc2)OCO5)cc1</smiles>

64 unnamed

Dreyer et al. 2001<smiles>COc1cc(OC)c2c(c1)O[C@]1(c3ccc(OC)c(O)c3)[C@H](c3ccccc3)c3c(nc4n(c3=O)CCC4)[C@]21O</smiles>

67 unnamed

Chaidir et al. 1999

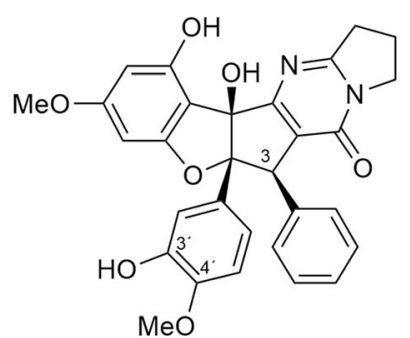

70 3'-hydroxymarikarin Greger et al. 2001<smiles></smiles>

73 aglaroxin $\mathrm{H}$ Molleyres et al. 1999

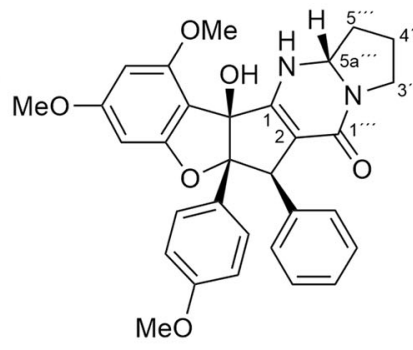

65 aglaiastatin Ohse et al. 1996

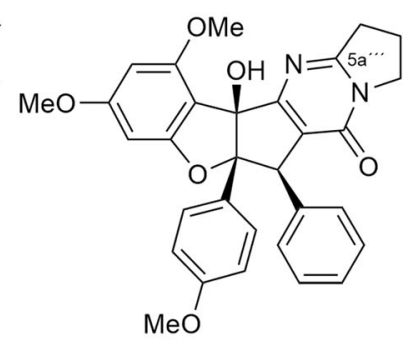

66 dehydroaglaiastatin Kokpol et al. 1994<smiles>COc1cc(OC)c2c(c1)O[C@]1(c3ccc(OC)c(OC)c3)[C@H](c3ccccc3)c3c(nc4n(c3=O)CCC4)[C@]21O</smiles>

68 aglaiformosanin Wang and Duh 2001<smiles>COc1ccc([C@H]2c3cc4c(c(OC)c3[C@H]2c2ccccc2)[C@]2(O)C3=C(C(=O)[C@@]2(c2ccc(OC)cc2)O4)N2CCC[C@H]2N3)cc1</smiles>

71 aglaroxin I Molleyres et al. 1999<smiles>COc1ccc([C@]23Oc4cc(OC)cc(O)c4[C@@]2(O)c2nc4n(c(=O)c2[C@@H]3c2ccccc2)CCC4)cc1</smiles>

69 marikarin Greger et al. 2001<smiles>COc1ccc([C@]23Oc4cc5c(c(OC)c4[C@@]2(O)c2nc4n(c(=O)c2[C@@H]3c2ccccc2)CCC4)OCO5)cc1</smiles>

72 aglaroxin C Molleyres et al. 1999<smiles>COc1ccc([C@]23Oc4cc5c(c(OC)c4[C@]2(O)c2nc4n(c(=O)c2[C@@H]3c2ccccc2)CCC4)OCO5)cc1OC</smiles>

74 aglaroxin $\mathrm{G}$ Molleyres et al. 1999<smiles>COc1ccc([C@]23Oc4cc(OC)cc(OC)c4[C@@]2(O)[C@H](O)[C@@H](C(=O)N[C@H]2CCCO2)[C@H]3c2ccccc2)cc1</smiles>

75 unnamed

Nugroho et al. 1997b 
Table 2 continued

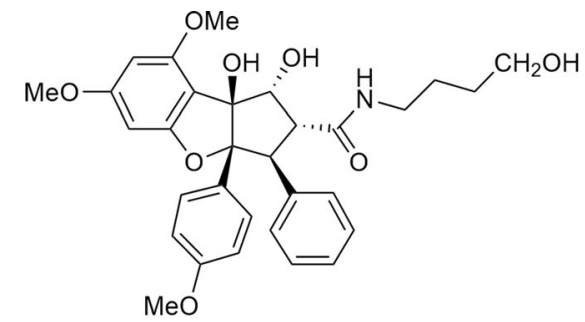

76 unnamed

Nugroho et al. 1997b

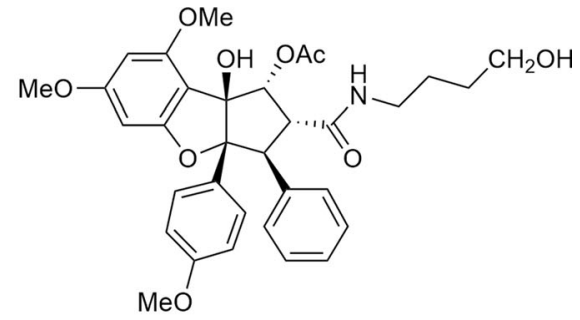

77 unnamed

Nugroho et al. 1997b
$C-5 \mathrm{a}^{\prime \prime \prime}$ and $N$. It is interesting to note that aglaiastatin (65), isolated from A. gracilis A.C. Smith, was converted into dehydroaglaiastatin (66) during purification by preparative TLC (Greger et al. 2001; Hausott et al. 2004). This indicates lower stability of compound 65 and possibly explains the more frequent reports on 66 and other corresponding dehydroderivatives. Although no amide-esters have been found so far as building blocks of flavaglines, closely related derivatives have been reported where amidealcohol derived moieties are incorporated into benzofurans (75-77). In this case one nitrogen atom of putrescine has obviously been replaced with oxygen as assumed for the aforementioned amide-esters isolated from A. tenuifolia (Fig. 4) (Greger et al. 2008).

With respect to the presumed central role of cinnamic acid in the formation of the flavagline basic skeleton (Fig. 1) rocagloic acid (1) and its congeners 2 and $\mathbf{3}$ may be regarded as biosynthetic precursors from which both the aglafoline-type ${ }^{2}$ (4-24) and the nitrogen-containing rocaglamide-type benzofurans (25-53) can be derived. Consequently, the rocaglaoltype derivatives (54-63) can be considered as the result of decarboxylation at $C-2$ (Table 2). The before mentioned fourth type of benzofurans is characterized by an incorporation of putrescine-derived amide moieties leading to the unnamed compounds 64, 7577 and the pyrimidinones 65-74. Different methylations of the amino-group in the rocaglamide-type flavaglines result in a series of corresponding

\footnotetext{
2 the name aglafoline (4) was published together with the correct chemical structure by Ko et al. (1992), whereas methyl rocaglate by Ishibashi et al. in the year 1993, so the compound name from Ko et al. takes priority.
}

desmethyl (32-37) and didesmethyl derivatives (3840, 49). Further grouping within the benzofurans is suggested by different substitution patterns of aromatic ring $\mathrm{A}$, showing either the two widespread methoxy groups in meta-position at $C-6$ and $C-8$, or a methylenedioxy group at $C-6, C-7$ combined with a methoxy group at $C-8$. The latter substitution pattern appears to be typical for a group of probably closely related Aglaia species and was also found in benzopyran and benzoxepine flavaglines (Tables 3, 4). Of special interest was the discovery of the unique structure of silvestrol (14) in the fruits and twigs of A. foveolata Pannell, published as A. silvestris (M. Roemer) Merrill. It deviates from the other flavaglines by an unusual dioxanyloxy moiety replacing the methoxy group at $C-6$ (Hwang et al. 2004). An acetylation of the $C-6^{\prime \prime \prime} \mathrm{OH}$ group of the dioxanyl ring was reported for aglapervirisin A (17) isolated from the leaf exract of Aglaia perviridis Hiern (An et al. 2016). Modified analogues of silvestrol (14) with a $\mathrm{CONH}_{2}$ group at $\mathrm{C}-2(\mathbf{4 1}, \mathbf{4 2})$ were recently isolated from this species along with four related derivatives, which are characterized by a new carbon skeleton with a fused 2,3-dihydrobenzofuran unit attached to the dioxanyl ring (43-46) (Agarwal et al. 2019). Another unusual substitution of ring $A$ is the replacement of the $C-8$ methoxy group by a hydroxy group in the marikarins $(\mathbf{6 9}, \mathbf{7 0})$, only known so far from $A$. gracilis (Greger et al. 2001). The substitution pattern of aromatic ring $\mathrm{B}$ is mostly characterized by one methoxy group in para-position at $C-4^{\prime}$, frequently accompanied by hydroxylation or methoxylation at $C$ $3^{\prime}$, and sometimes, by the formation of a methylenedioxy group at $C-3^{\prime}, C-4^{\prime}$. A threefold substitution of 
Table 3 Benzopyran flavaglines

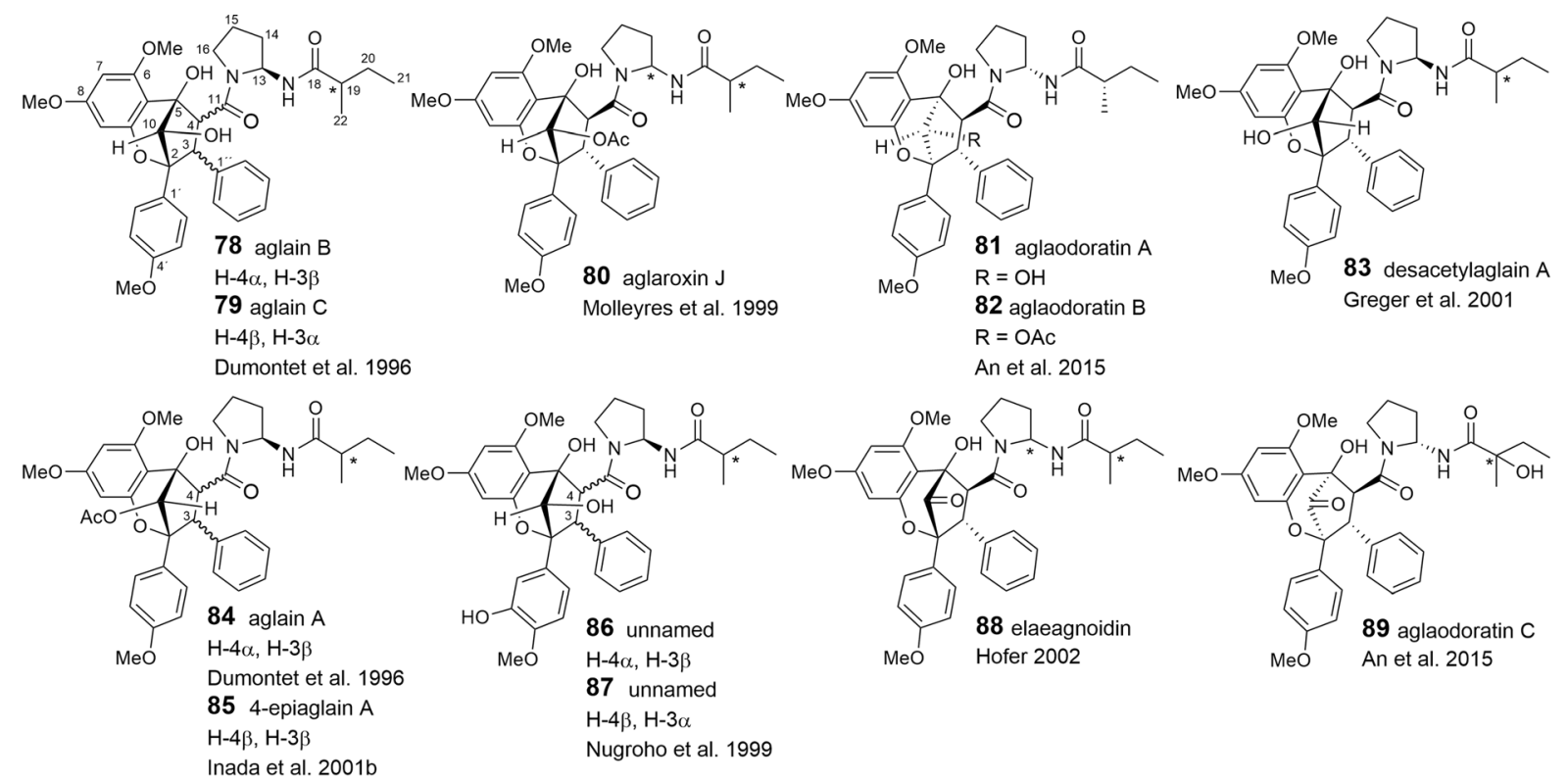

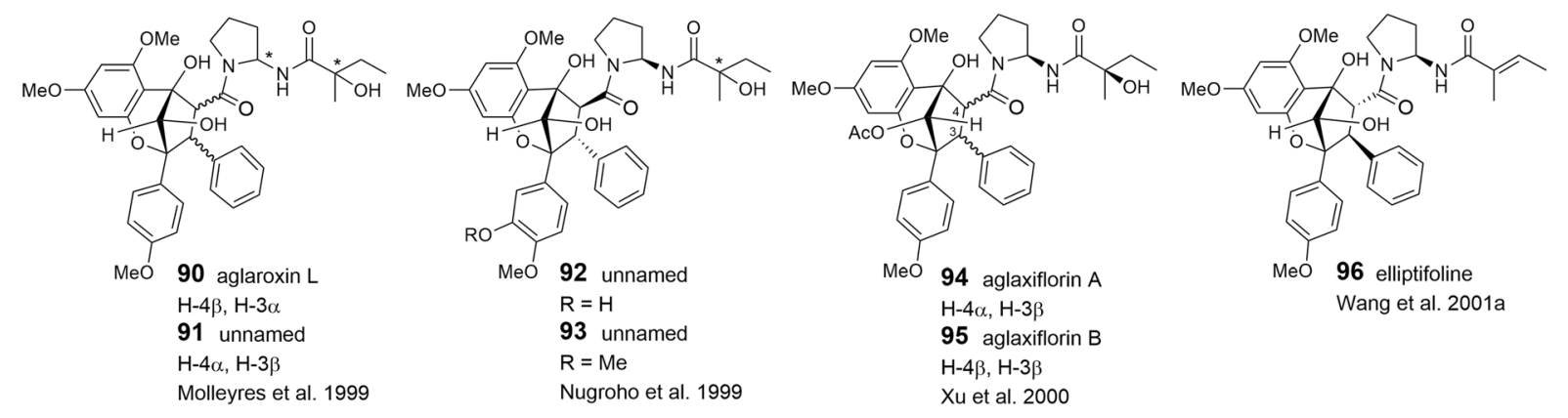

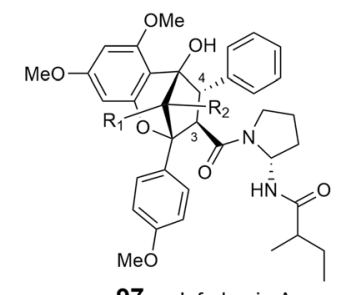

97 aglaforbesin $\mathrm{A}$ $\mathrm{R}_{1}=\mathrm{OH}, \mathrm{R}_{2}=\mathrm{H}$ 98 aglaforbesin $\mathrm{B}$ $\mathrm{R}_{1}=\mathrm{H}, \mathrm{R}_{2}=\mathrm{OH}$ Dumontet et al. 1996<smiles>CCC(C)C(=O)NC1CCCN1C(=O)[C@@](O)(c1ccc(OC)cc1)[C@@](O)(c1ccccc1)c1c(O)cc(O)cc1OC</smiles>

99 aglaodoratin D An et al. 2015

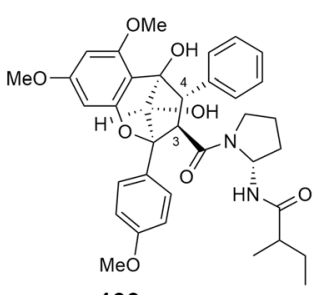

100 aglaodoratin $F$ An et al. 2015

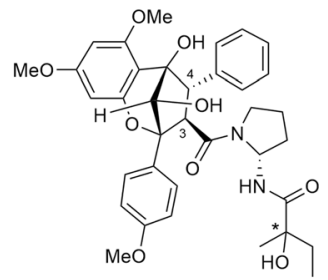

101 aglaodoratin $\mathrm{E}$ An et al. 2015 
Table 3 continued<smiles>CCC(C)(CC)C(=O)NC1CCCN1C(=O)C1(O)C(O)(O)C(O)(c2ccc(OC)cc2OC)C(O)(c2ccccc2)C1(O)c1ccc(OC)cc1</smiles>

102 aglaxiflorin $C$ $\mathrm{Xu}$ et al. 2000

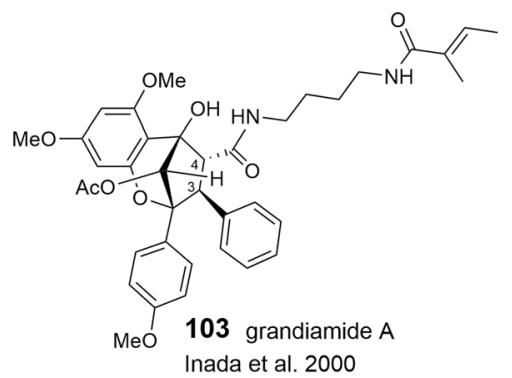

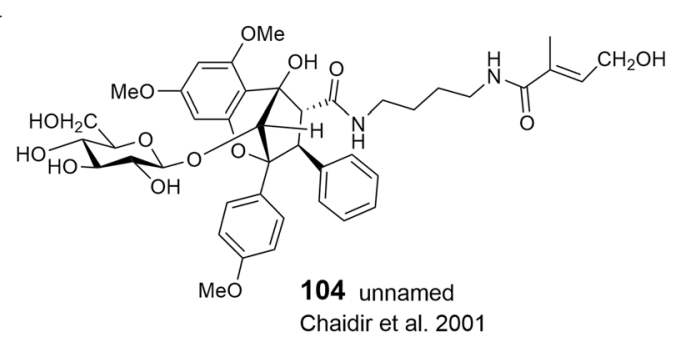

$$
\mathrm{MeO}
$$

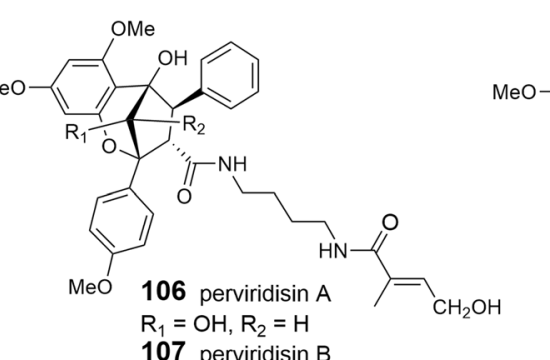
107 perviridisin $\mathrm{B}$ $\mathrm{R}_{1}=\mathrm{H}, \mathrm{R}_{2}=\mathrm{OH}$

Pan et al. 2013

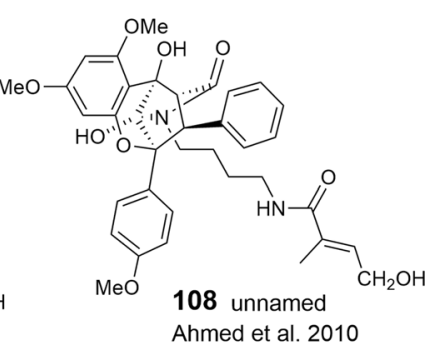

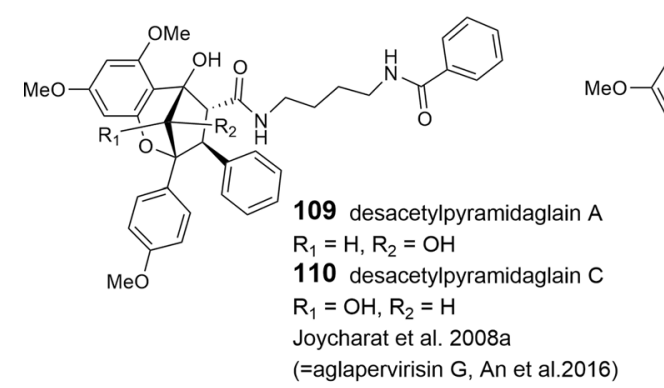

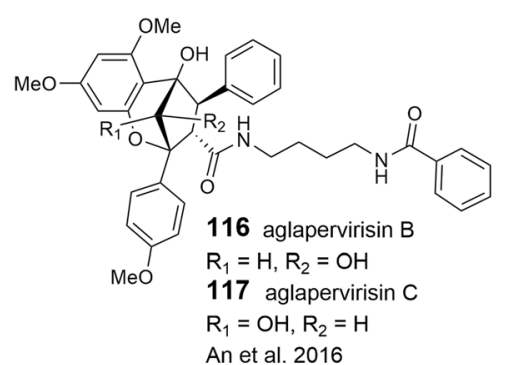

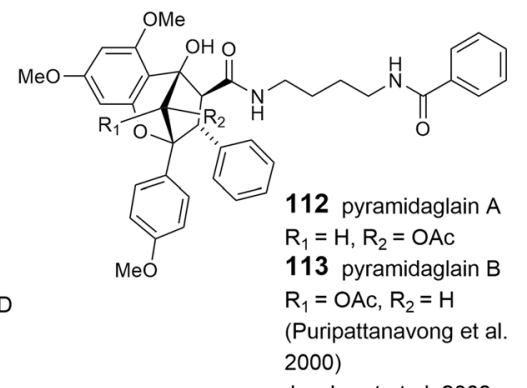

Joycharat et al. 2008a 
Table 3 continued<smiles>COC(=O)C1C(O)(c2ccc(OC)cc2)C(C(=O)O)C(O)(c2ccc(OC)cc2)C1(O)c1ccccc1</smiles><smiles>COc1ccc(C2(O)C(C(=O)NCCCCNC(=O)Cc3ccc(O)cc3)C(c3ccccc3)C(c3ccc(OC)cc3OC)C2(O)c2ccccc2)cc1</smiles><smiles>COc1ccc(C2(O)C(C(=O)N3CCCC3NC(=O)CC(C)C)C(O)(c3ccccc3)C(O)(c3ccc4c(c3OC)OCO4)C2(O)O)cc1</smiles>

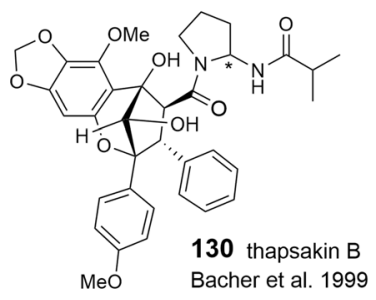

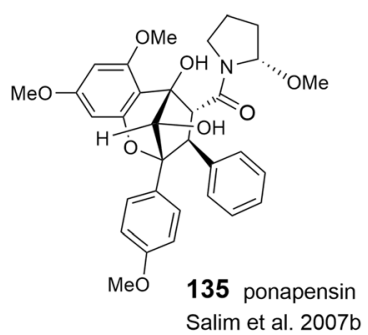<smiles>COc1ccc(C(=O)[C@H](c2ccccc2)[C@@H](C(=O)NCCCCNC(=O)c2ccccc2)C(O)c2c(O)cc(OC)cc2OC)cc1</smiles><smiles>CCC(C)C(=O)NC1CCCN1C(=O)C(O)C(O)(c1ccc2c(c1OC)OCO2)C(O)(c1ccc(OC)cc1)C(O)(c1ccccc1)c1ccccc1</smiles>

Bacher et al. 1999

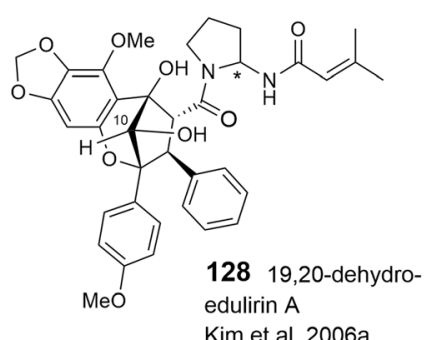

edulirin A<smiles>COc1ccc(C2(O)C(C(=O)NCCCCNC(=O)c3ccc(O)cc3)C(c3ccccc3)C(O)(c3ccc(OC)cc3OC)C2(O)c2ccccc2)cc1</smiles>

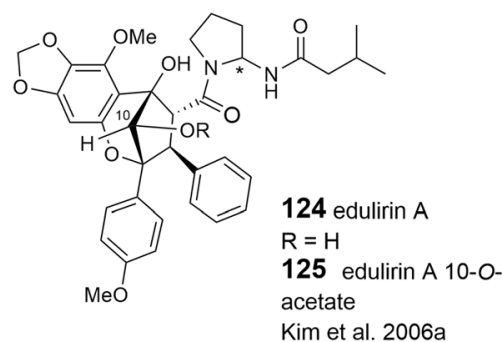<smiles>COc1ccc(C2(O)C(c3ccccc3)C(O)(c3ccc4c(c3OC)OCO4)C(O)(C(=O)N3CCCC3NC(=O)C(C)C)C2(O)O)cc1</smiles>
Bacher et al. 1999

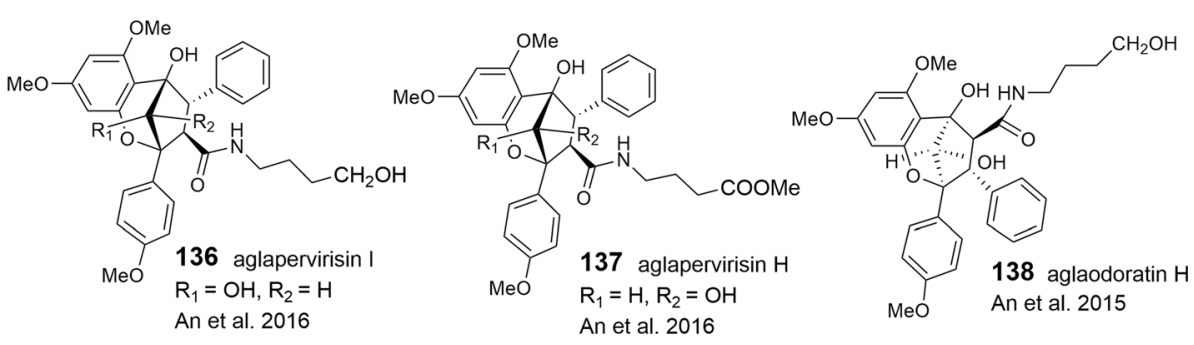

*Epimers not determined 
Table 4 Benzoxepines
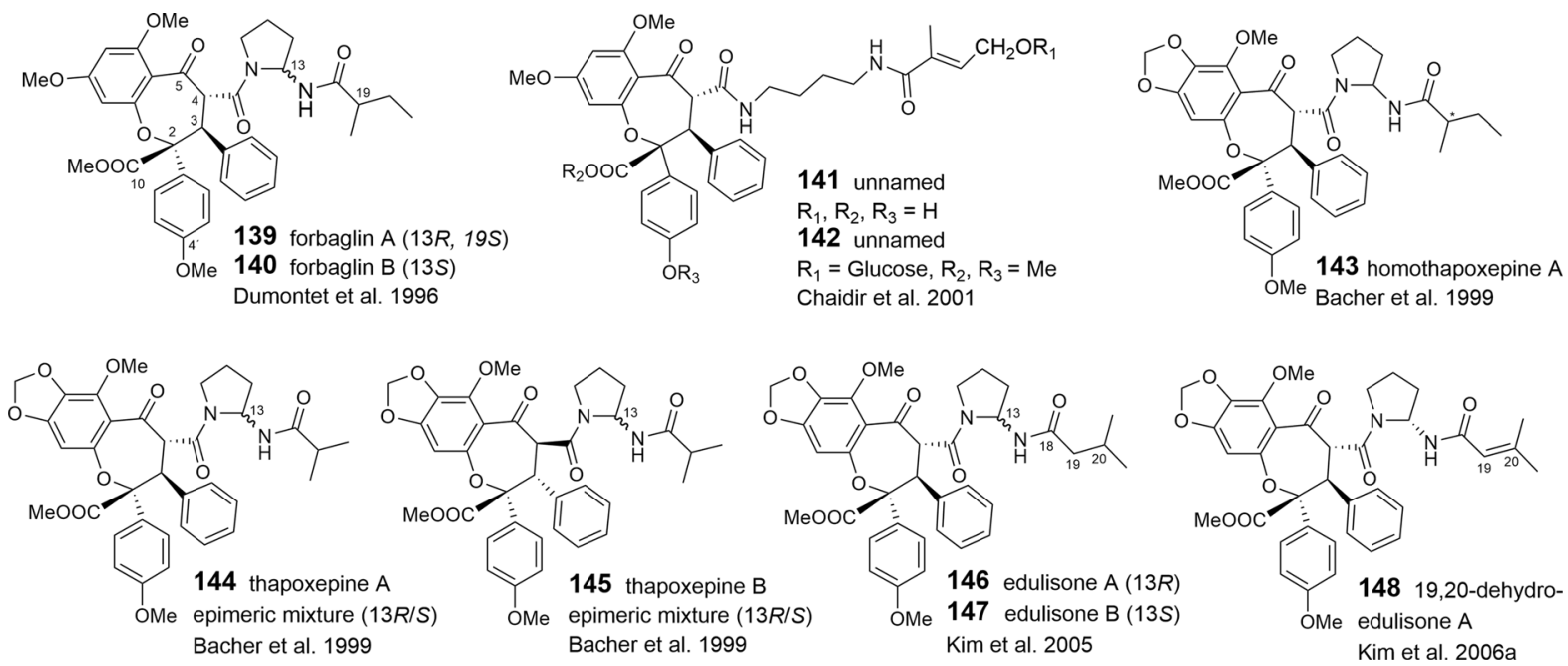

ring $\mathrm{B}$ at $\mathrm{C}-2^{\prime}, \mathrm{C}-3^{\prime}, \mathrm{C}-4^{\prime}$ was reported only for aglaroxin $\mathrm{F}$ (52), isolated from A. elaeagnoidea (A. Juss.) Benth. (= A. roxburghiana (Wight \& Arn.) Miq.) (Molleyres et al. 1999), and for cyclorocaglamide (53) from A. oligophylla Miq. (Bringmann et al. 2003). The latter represents the first flavagline with an oxygen bridge between $C-8 \mathrm{~b}$ and $C-2^{\prime}$ of the aromatic ring $\mathrm{B}$.

An important structural variation in the benzofurans is created by different substitutions of the hydroxy groups at $C-1$ and $C-8 \mathrm{~b}$ of the cyclopentane ring. While the former is frequently esterified with acetyl- $(6,9,20,23,26,28,33,36,39,48,49,51,55$, 77) or formyl-residues $(\mathbf{2}, \mathbf{5}, \mathbf{8}, \mathbf{1 9})$, the latter can be substituted by a methoxy- $(11,21,29,34,49,56,62)$ or ethoxy-group $(\mathbf{3 0}, \mathbf{3 7}, \mathbf{5 7})$. Rare chemical features are represented at $C-1$ by the formation of oximes in the unnamed derivative 13 (Nugroho et al. 1999) and in rocaglamide AY (12) (Duong et al. 2014), or by an insertion of an oxo-group in 63 (Cui et al. 1997) and 64 (Dreyer et al. 2001). Glycosylation has been reported so far only for the hydroxy group at C- $3^{\prime}$ of aromatic

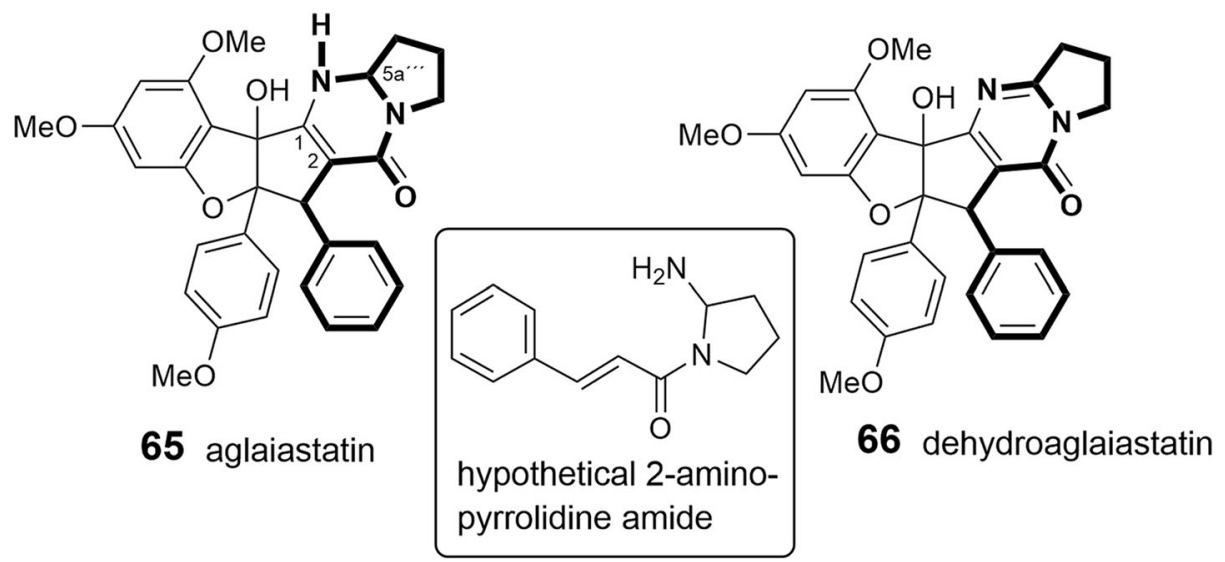

Fig. 3 Formation of pyrimidinones with a hypothetical putrescine-derived 2-aminopyrrolidine amide (Greger et al. 2008) 

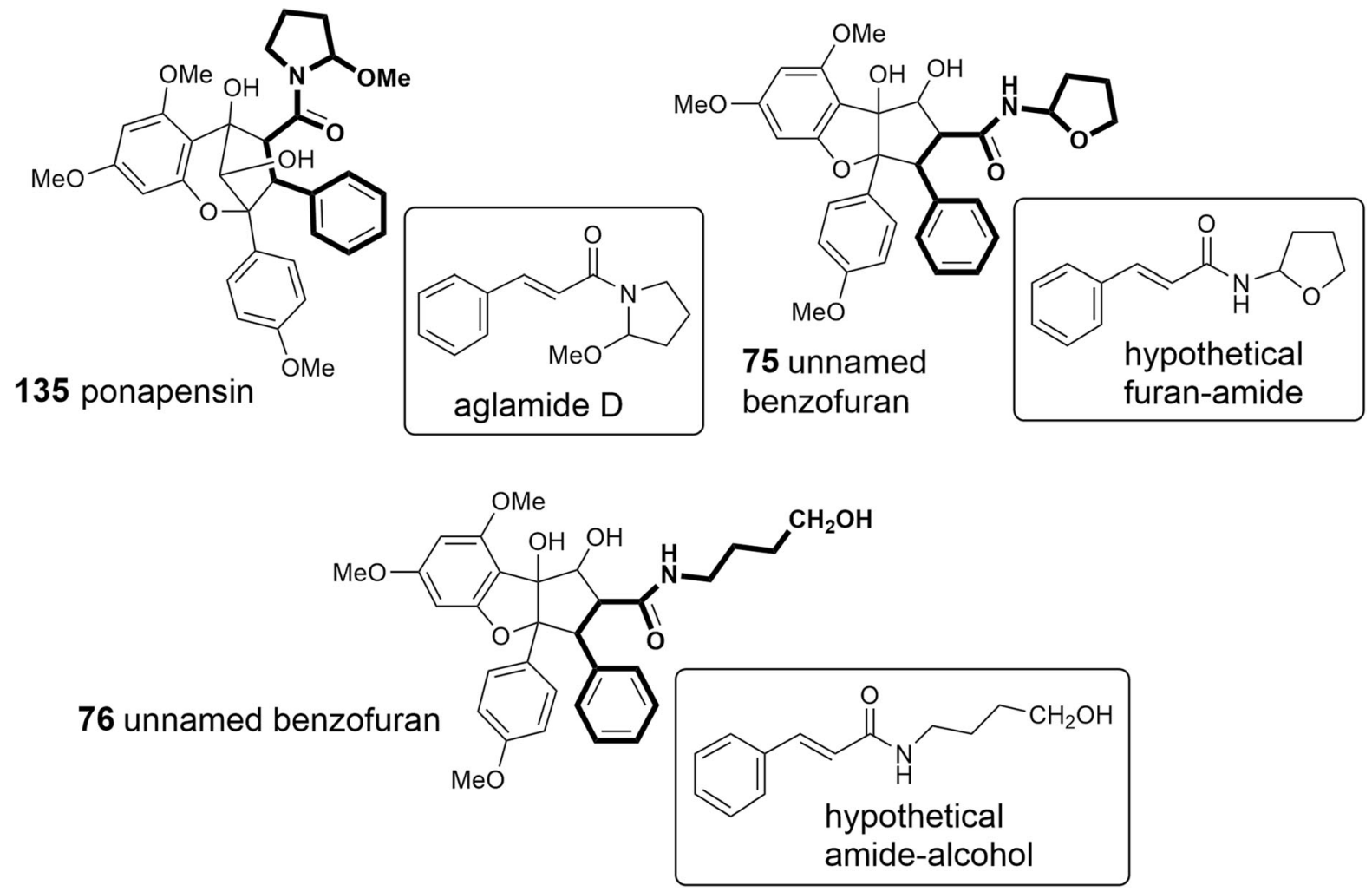

Fig. 4 Benzopyran- and benzofuran-type flavaglines with amide-alcohol derived moieties

ring B in the unnamed derivatives $\mathbf{5 9}$ (Nugroho et al. 1997b) and 60 (Xu et al. 2000).

Benzopyran and benzoxepine flavaglines

The structural variation of the benzopyrans and benzoxepines is mainly formed by different bisamide parts attached to the basic skeleton. Apart from cyclized or open-chained putrescine moieties (Table 1A, B), the differences are created by different acid residues. As shown in Tables 3 and 4, derivatives with 2-methyl butyric acid are dominating in the benzopyrans 78-108 and benzoxepines 139-143, displaying additional variation by hydroxylation and dehydration (tiglic acid) of the acid part. Isobutyric (129-134, 144, 145), isovaleric (124-127, 146, 147), and senecioic acid residues $(\mathbf{1 2 8}, \mathbf{1 4 8})$ were also found in benzopyrans and benzoxepines, where they are linked to cyclized putrescine only. By contrast, benzoic acid residues are uniformly linked to openchained putrescine only found in the benzopyrans 109-120. Aglapervirisins F (121) and E (122), isolated from the leaves of $A$. perviridis Hiern, differ by parahydroxylated benzoic or phenylacetic acid parts, respectively (An et al. 2016). In the coexisting aglapervirisins I (136) and $\mathrm{H}$ (137), as well as in ponapensin (135) (Salim et al. 2007b), the putrescine derived bisamides are replaced by other residues presumably derived from amide-alcohol precursors (Fig. 3).

Apart from the two different substitution patterns of aromatic ring A, already mentioned for the benzofurans, additional variation in the benzopyrans and benzoxepines is created by different configurations at $C-3$ and $C-4$, and substitutions and stereochemistries of the hydroxy group at $C-10$ in the benzopyrans. Rare structural transformations are featured by cyclofoveoglin (119), isolated from the stem bark of $A$. foveolata (Salim et al. 2007a), and the unnamed benzopyran 108 from the leaves of A. cucullata (Roxb.) Pellegrin (Ahmed et al. 2010). Both are formed by a cyclization reaction between $N-12$ of the bisamide moiety and $C-10$ of the basic skeleton. Ringopening leads to the formation of secofoveoglin (120), 
therapeutic agent for B-cell malignancies including chronic lymphocytic leukemia, being more potent against B-cells than T-cells (Lucas et al. 2009)

stimulated interaction of elF4A with mRNA preventing successful assembly of the mRNA/elF4A dimer with the eIF4F translation initiation complex

(Bordeleau et al. 2008)

potent inhibitor of cap-dependent viral mRNA translation in Corona virus (CoV) (Müller et al. 2018)

possesses comparable cytotoxic potencies to those of the well-known natural anticancer compounds paclitaxel (Taxol) and camptothecin (Hwang et al. 2004)

(Muller etal. 2018)

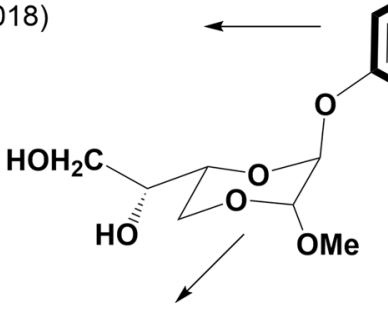

blocks replication of different subgenomic replicons of Hepatitis E virus (HEV) at low nanomolar concentrations (Todt et al. 2018)

inhibited infection of Ebola virus (EBOV) in human macrophages, being non-toxic in the tested cell systems (Biedenkopf et al. 2017)

Fig. 5 Anticancer and antiviral activities of silvestrol (14)

which may also be interpreted as a benzoxepine derivative (Salim et al. 2007a). Glycosylation has been reported for the two benzopyrans $\mathbf{1 0 4}$ and $\mathbf{1 0 5}$, and the benzoxepine 142, which were isolated from the leaf extract of the Chinese A. dasyclada Miq. From the same extract the related derivative $\mathbf{1 4 1}$ was shown to differ from 142 by the absence of the glucose moiety and two methoxyl groups at $C-4^{\prime}$ and $C$-10 (Chaidir et al. 2001).

\section{Bioactivities}

Insecticidal activities

The prerequisite for the high insecticidal activity of flavaglines was the formation of a cyclopentabenzofuran basic skeleton. In contrast, benzopyran and benzoxepine flavaglines did not show significant effects (Bacher et al. 1999; Nugroho et al. 1999; Molleyres et al. 1999; Dreyer et al. 2001). The first four active derivatives, rocaglamide (25), desmethylrocaglamide (32), aglafoline (= methyl rocaglate) (4), and rocaglaol (54), were obtained by bioassay-guided isolation from the twigs and leaves of $A$. odorata Lour. (Janprasert et al. 1993; Ishibashi et al. 1993). In order to investigate the insecticidal and anti-feeding properties of various derivatives and to determine structure-activity relationships a representative number of benzofurans were tested in the following studies against the polyphagous pest insect Spodoptera littoralis. The very high activity of didesmethylrocaglamide (38) with survival rate $\left(\mathrm{LC}_{50}\right)$ and growth inhibition $\left(\mathrm{EC}_{50}\right)$ values at $0.8 \mathrm{ppm}$ and $0.05 \mathrm{ppm}$, respectively, was comparable with that of the wellknown natural insecticide azadirachtin with $0.9 \mathrm{ppm}$ and $0.04 \mathrm{ppm}$ (Nugroho et al. 1997b). On the basis of comparative feeding experiments it became apparent that especially different substitutions of the $\mathrm{OH}$ groups at $C-8 \mathrm{~b}$ and $C-1$ of the cyclopentane ring are essential for insecticidal activity. As shown in Fig. 5 acetylation at $C-1$ reduced the $\mathrm{LC}_{50}$ value of rocaglamide (25) from $0.9 \mathrm{ppm}$ to $7.1 \mathrm{ppm}$, and of aglafoline (4) from $1.3 \mathrm{ppm}$ to $6.62 \mathrm{ppm}$. This reducing effect by substituting the $\mathrm{OH}$-group at $\mathrm{C}-1$ by an $O A c-g r o u p$ was also shown in the related derivatives 9, 33, and 36, which were approximately sevenfold less active than their corresponding non-acetylated derivatives (Nugroho et al. 1997a; Güssregen et al. 1997; Hiort et al. 1999; Chaidir et al. 1999), and was also confirmed for 1-O-acetylpannelline (23) with a different substitution pattern in aromatic ring $\mathrm{A}$ (Brader et al. 1998). Similarily, the two $C$-1 formylated derivatives $\mathbf{5}$ and $\mathbf{8}$ were shown to be five times 


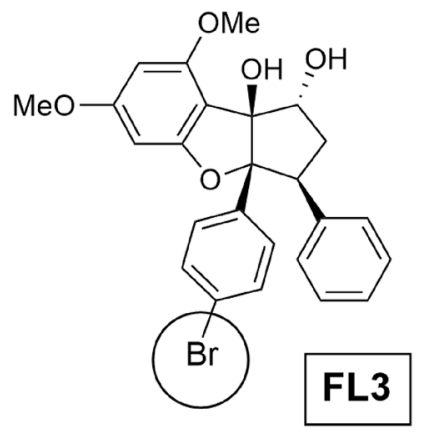

Thuaud et al. 2009

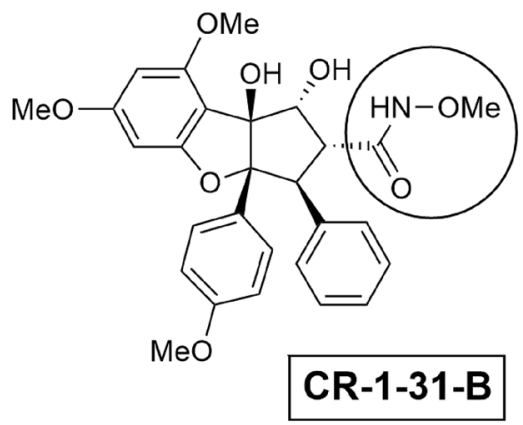

Rodrigo et al. 2012

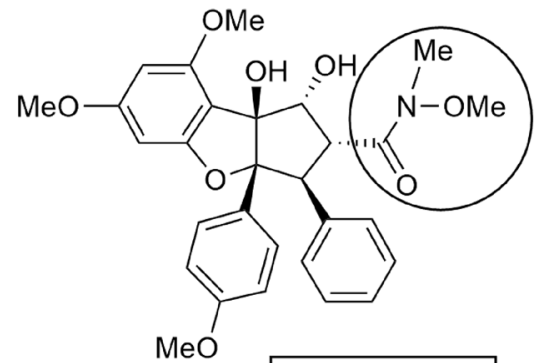

ROHINITIB

Santagata et al. 2013

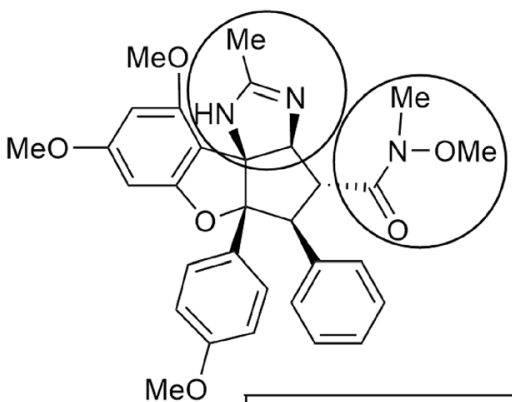

CMLD0126112

Chu et al. 2019

Fig. 6 Synthetic flavaglines with high anti-proliferative activity. Encircled substituents indicate structural differences to the corresponding naturally occurring parent compounds rocaglaol (54) and rocaglamide (25)

less active than the corresponding non-substituted derivatives 4 and 7 (Schneider et al. 2000). An even stronger effect was observed by replacing the $\mathrm{OH}$ group at $C$-8b. After substitution by a methoxy-group in 8b-methoxyaglafoline (11) and 8b-methoxyrocaglaol (56) no activity could be determined in both compounds up to a cocentration of $100 \mathrm{ppm}$. This intriguing effect was also confirmed for the derivatives $\mathbf{3 0}$ and $\mathbf{3 7}$ containing an ethoxy-group at $C-8 \mathrm{~b}$ (Chaidir et al. 1999). While the different substituents at $C-2$, leading to ester (aglafoline-type) or amide groups (rocaglamide-type), revealed only marginal influences, the unsubstituted $C$-2 (rocaglaol-type) showed a clear decrease of activity (Fig. 5) (Hiort et al. 1999; Bacher et al. 1999; Schneider et al. 2000; Ebada et al. 2011).

Modifications of the substitution pattern of aromatic ring A showed higher activity for compounds with dimethoxylation at $C-6$ and $C-8$ than those with a $C-6, C-7$ methylenedioxy substitution combined with a methoxy-group at $C-8$ (Bacher et al. 1999; Molleyres et al. 1999; Dreyer et al. 2001). These two substitution patterns were shown to lead to a different mode of action in the otherwise identical derivatives rocaglamide (25) and aglaroxin A (47) (Koul et al. 2004, 2005). The replacement of the $C-8$ methoxygroup of aglaiastatin (65) by a hydroxy-group in marikarin (69) reduced the $\mathrm{LC}_{50}$ value from 1.2 to $12.2 \mathrm{ppm}$ (Greger et al. 2001). A reduction of activity was also observed by additional substitutions in aromatic ring B (Molleyres et al. 1999; Schneider et al. 2000). Preparation of synthetic benzofurans showed that analogues of rocaglamide (25) with equal or improved insecticidal activity could not be achieved (Li et al. 2008; Hall et al. 2017) (Table 5).

Antiproliferative activities

Inspired by the significant antileukemic activity of the alcoholic extract from stems and roots of A. rimosa (= A. elliptifolia), King et al. (1982) examined the chloroform-soluble fraction to identify the active principle. They isolated and identified the first benzofuran flavagline, named rocaglamide (25), which 
Table 5 Insecticidal activities against Spodoptera littoralis

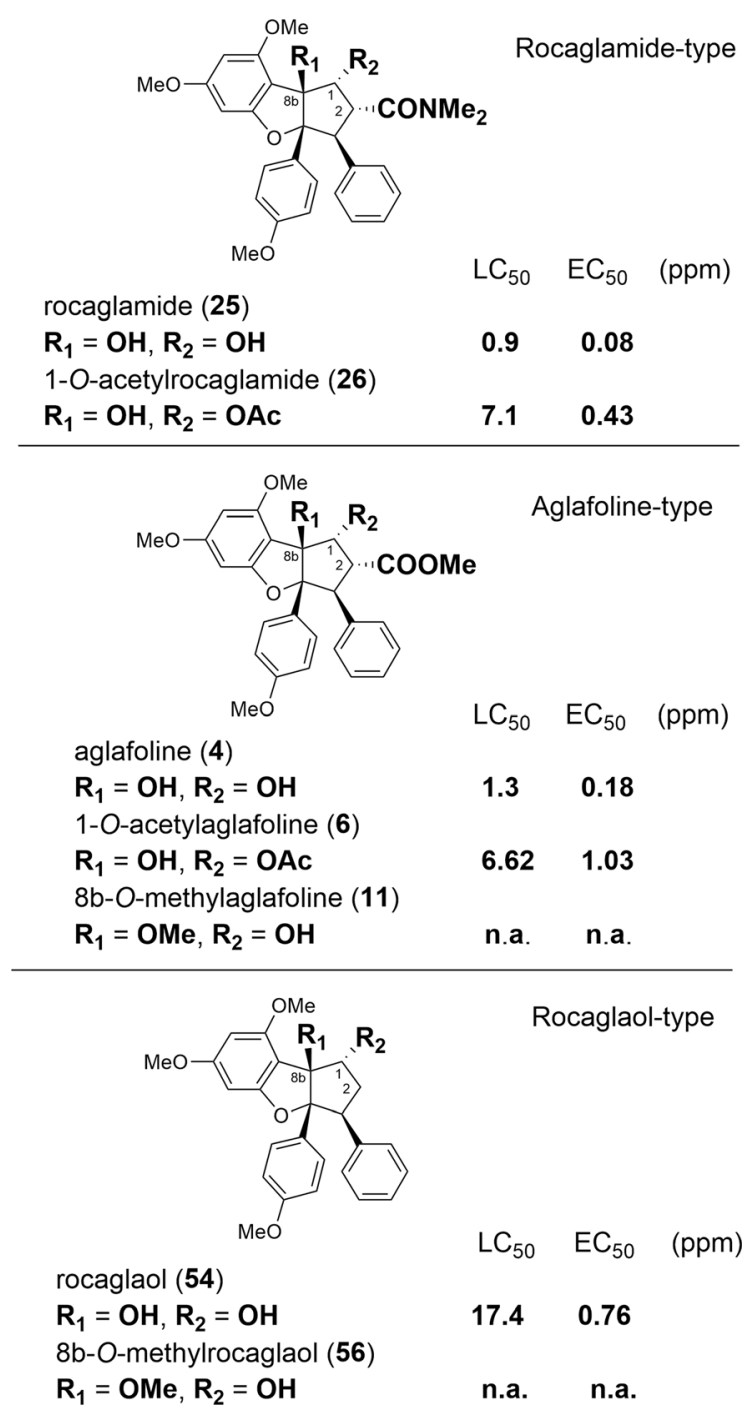

n.a. $=$ not active up to a concentration of 100 ppm (Hiort et al. 1999; Chaidir et al. 1999)

showed high activity against P388 lymphocytic leukemia. In spite of this pronounced activity further research on antitumor properties of flavaglines only started 14 years later, when Dumontet et al. (1996) reported on the strong cytotoxic activity of didesmethylrocaglamide (38) with an inhibitory concentration $\left(\mathrm{IC}_{50}\right)$ value of $6.0 \mathrm{ng} / \mathrm{ml}$ with $\mathrm{KB}$ (oral epidermoid carcinoma) cells. Since then different research groups investigated the inhibitory effects of flavaglines in different tumor cells. In the following year Wu et al. (1997) reported on the high cytotoxicity of aglafoline (4) and rocaglamide (25), isolated from the stems of $A$. rimosa, against six cancer cell lines with $\mathrm{IC}_{50}$ values in the range of $1-7 \mathrm{ng} / \mathrm{ml}$. Structureactivity relationships were observed in five benzofurans, isolated from the fruits and stems of A. elliptica Blume (Cui et al. 1997). Structurally, they were shown to represent aglafoline $(4,18,19)$ - and rocaglaol-type derivatives $(\mathbf{6 1}, \mathbf{6 3})$. Apart from aglafoline (4) itself, they deviate from the parent compounds by a methylenedioxy group at $C-3^{\prime}-\mathrm{C}-4^{\prime}$ of the B-ring, and different substituents at $C-1$. As shown in Table 6 all compounds were active in various human tumor cell lines, but the responses mediated by the three aglafoline-type derivatives 4,18 , and 19 were particularly potent with $\mathrm{IC}_{50}$ values in the range of $1-30 \mathrm{ng} /$ $\mathrm{ml}$. Here, 4'-demethoxy-3',4'-methylenedioxyaglafoline (18) showed the highest cytotoxicity against glioblastoma (U373) and breast cancer (BC1) cell lines with $\mathrm{IC}_{50}$ values at 0.8 and $0.9 \mathrm{ng} / \mathrm{ml}$, respectively, whereas aglafoline (4) itself showed lower values at 10.0 and $3.0 \mathrm{ng} / \mathrm{ml}$. By contrast, the loss of a substituent at $C$-2 in the rocaglaol-type derivatives $\mathbf{6 1}$ and 63 clearly showed less activity. In BC1 cells compound $\mathbf{6 1}$ exhibited an $\mathrm{IC}_{50}$ value only at $200.0 \mathrm{ng} / \mathrm{ml}$, while in 63 the replacement of the $\mathrm{OH}$ group at $C$ - 1 by an oxo-group led to an even bigger reduction at $1400.0 \mathrm{ng} / \mathrm{ml}$. It is interesting to note, that $3^{\prime}, 4^{\prime}$-methylenedioxy substitution in ring B led here to a more potent activity (Table 6), while the presence of a $3^{\prime}-\mathrm{OH}$ or $3^{\prime}$-OMe group in the derivatives $7,27,28$, $31,35,36,40$ functions as a negative factor (Bohnenstengel et al. 1999a). The remarkable cytotoxicity of the aglafoline-type derivative $\mathbf{1 8}$ led to a mechanistic study of its activity and to in vivo testing of selected compounds. In accord with the in vitro results compound 18 inhibited the growth of $\mathrm{BC} 1$ cells implanted in athymic mice. As demonstrated with clonogenic and cell proliferation assays performed by treating lung cancer cells (Lu1) with compound $\mathbf{1 8}$, growth inhibitory activity was reversible, and cells retained viability. These tests suggested that compound 18 functions by a cytostatic mechanism, probably due to inhibition of protein biosynthesis, rather than inducing necrosis or apoptosis (Lee et al. 1998).

Structure-activity relationships were also shown by testing eleven benzofurans and one benzopyran for growth inhibiting properties against the two human 
Table 6 Growth inhibitory potential of five benzofuran flavaglines with various human cancer cell lines ${ }^{\mathrm{a}}$

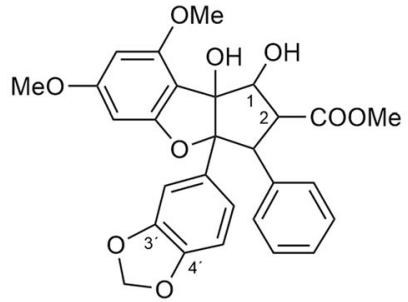

$184^{\prime}$-demethoxy-3',4'methylenedioxyaglafoline $\mathrm{IC}_{50}[\mathrm{ng} / \mathrm{ml}]$ :

$\begin{array}{rlrl}\underline{\mathbf{0 . 9}} & \mathrm{BC} 1 & \mathbf{6 . 0} & \mathrm{KB} \\ \mathbf{1 0 . 0} & \mathrm{HT}-1080 & 10.0 & \mathrm{~A} 431 \\ \mathbf{5 . 0} & \mathrm{Lu} 1 & \mathbf{2 . 0} & \mathrm{LNCaP} \\ \mathbf{6 0 . 0} & \mathrm{Mel} 2 & \mathbf{2 . 0} & \mathrm{ZR}-75 \\ 10.0 & \mathrm{Col} 2 & \underline{0.8} & \text { U373 }\end{array}$<smiles>COC(=O)C1=C(c2ccccc2)C2(c3ccc4c(c3)OCO4)Oc3cc(OC)cc(OC)c3C1(O)C2=O</smiles>

19 1-O-formyl-4'-demethoxy$3^{\prime}, 4^{\prime}$-methylenedioxyaglafoline $\mathrm{IC}_{50}[\mathrm{ng} / \mathrm{ml}]$ :
3.0 BC1
$30.0 \mathrm{~KB}$
3.0 HT-1080 3.0 A431
1.0 Lu1
30.0 LNCaP
$1.0 \mathrm{Mel} 2$
$120.0 \mathrm{ZR}-75$
$2.0 \mathrm{Col} 2$
3.0 U373<smiles>COc1ccc(C2C(c3ccccc3)=C(C(C)=O)C3(O)c4c(OC)cc(OC)cc4OC23O)cc1</smiles>

4 aglafoline

$\mathrm{IC}_{50}[\mathrm{ng} / \mathrm{ml}]:$

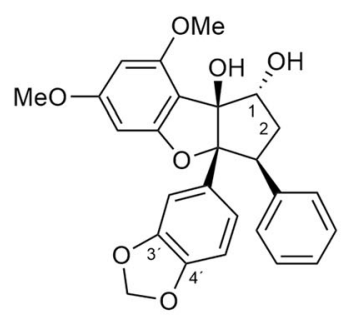

$614^{\prime}$-demethoxy-3', 4'methylenedioxyrocaglaol $\mathrm{IC}_{50}[\mathrm{ng} / \mathrm{ml}]$ :

$\begin{aligned} 200.0 & \text { BC1 } & 90.0 & \text { KB } \\ \text { NT } & \text { HT-1080 } & \text { NT } & \text { A431 } \\ 70.0 & \text { Lu1 } & \text { NT } & \text { LNCaP } \\ \text { NT } & \text { Mel2 } & \mathbf{8 6 . 0} & \text { ZR-75 } \\ 70.0 & \text { Col2 } & \text { NT } & \text { U373 }\end{aligned}$<smiles>COc1cc(OC)c2c(c1)O[C@]1(c3ccc4c(c3)OCO4)[C@H](c3ccccc3)C=C(O)[C@@]21O</smiles>

63 1-oxo-4'-demethoxy$3^{\prime}, 4^{\prime}$-methylenedioxyrocaglaol

\begin{tabular}{|c|c|c|}
\hline \multicolumn{3}{|c|}{$\mid \mathrm{C}_{50}[\mathrm{ng} / \mathrm{ml}]:$} \\
\hline 1400.0 & $\mathrm{BC} 1$ & $200.0 \mathrm{~KB}$ \\
\hline NT & HT-1080 & NT A431 \\
\hline 100.0 & Lu1 & $70.0 \mathrm{LNCaP}$ \\
\hline NT & Mel2 & NT ZR-75 \\
\hline 200.0 & $\mathrm{Col} 2$ & NT U373 \\
\hline
\end{tabular}

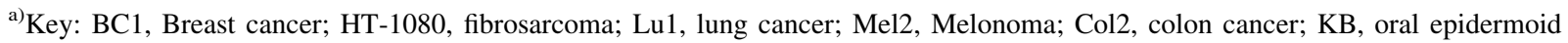
carcinoma; A431, epidermoid carcinoma; LNCaP, hormon dependent prostate cancer; ZR-75, hormon dependent breast cancer; U373, glioblastoma; NT, not tested (Cui et al. 1997; Lee et al. 1998)

cancer cell lines MONO-MAC-6 (monocytic leukemia) and MEL-JUSO (melanoma) (Bohnenstengel et al. 1999a). While the benzopyran aglain (78/79) was shown to be completely inactive, all of the benzofurans studied exhibited pronounced antiproliferative activity. The most active compound was didesmethylrocaglamide (38) with $\mathrm{IC}_{50}$ values at $2.0 \mathrm{ng} / \mathrm{ml}$ with MONO-MAC- 6 , and $6.0 \mathrm{ng} / \mathrm{ml}$ with MEL-JUSO, and is thus comparable with the wellknown anticancer drug vinblastine sulfate. A slight decrease of activity was observed by replacing the $\mathrm{CONH}_{2}$-group of $\mathbf{3 8}$ by larger substituents, and the acetylation of the $\mathrm{OH}$ group at $C$-1. A negative influence was also observed by the insertion of $O H$ or $O \mathrm{Me}$ at $C-3^{\prime}$ of the B-ring (Bohnenstengel et al. 1999a). Further studies indicated a complete loss of antiproliferative activity by replacing the $\mathrm{OH}$ at $\mathrm{C}-8 \mathrm{~b}$ by a methoxy group in compounds 11 and 56. Comparing these findings with those reported for insecticidal activities (Table 5), it is conceivable to assume that the molecular mechanisms of flavaglines are similar or identical both in insects and human cancer cells (Bohnenstengel et al. 1999b). 
From six flavaglines, isolated from the leaf extract of the Malaysian A. laxiflora Miq., only the two benzofurans, rocaglaol (54) and its $3^{\prime}$-rhamnoside (60), showed significant activity against a panel of cancer cell lines, while the four benzopyrans 90, 94, 95, and $\mathbf{1 0 2}$ were inactive. This study reported for the first time on the cytotoxicity of a flavagline glycoside (Xu et al. 2000). The $C$-2 unsubstituted rocaglaol (54) was later also isolated as the main cytotoxic constituent from the bark of A. crassinervia Kurz ex Hiern. In contrast to previous results, where the loss of the carboxy group at $C-2$ led to a decrease of activity in 61 and 63 (Lee $t$ al. 1998), the high $\mathrm{ED}_{50}$ values of rocaglaol (54) itself against Lu1 (lung cancer), LNCaP (hormone-dependent prostate cancer), and MCF-7 (breast cancer) were comparable to those of the positive controls, paclitaxel (Taxol $\left.{ }^{\circledR}\right)$, and camptothecin. Moreover, compound $\mathbf{5 4}$ was found to be selectively ( $>330$-fold) active against the three cell lines, when compared with the non-tumorigenic HUVEC cell line (Su et al. 2006). Further experiments showed that it represents a potent cytotoxic agent that induces cell cycle arrest at the $\mathrm{G}_{2} / \mathrm{M}$-phase and apoptosis through the mitochondrial pathway (Mi et al. 2006a). Cytotoxic activities against Lu1, LNCaP and MCF-7 cells in the range of $\mathrm{ED}_{50}$ values at 0.001 to $0.8 \mu \mathrm{g} / \mathrm{ml}$ were also reported for aglaroxin A (47), 1-O-acetylaglaroxin A (48), and 1-O-acetylaglaroxin B (51), all of which are characterized by a 8-methoxy6, 7-methylenedioxy substitution of the aromatic ring A (Kim et al. 2006a).

Significant cytotoxicity was also determined for rocagloic acid (1) from the leaves of A. rimosa, representing a benzofuran with a free carboxy group at C-2 (Wang et al. 2001a, b). Compound $\mathbf{1}$ was later also isolated from the twigs of A. rubiginosa (Hiern) $\mathrm{C}$. M. Pannell together with the $C-2$ methylesters aglafoline (4) and 1-O-acetylaglafoline (6), and the $C-2$ unsubstituted 1- $O$-acetylaglaol (55). All four compounds exhibited broad cytotoxic activity, with $\mathrm{ED}_{50}$ values in the range of 63-325 nmol against a panel of human cancer cell lines (Rivero-Cruz et al. 2004). Using a colorimetric method the cytotoxic properties of seven flavaglines, isolated from the fruits of $A$. cucullata (Roxb.) Pellegrin, were evaluated against $\mathrm{KB}$ (oral epidermoid carcinoma), BC (breast cancer), and NCI-H187 (small cell lung cancer) cell lines. In this assay, the rocagloic acid derivatives $\mathbf{2}, \mathbf{3}$, the aglafoline-type derivatives $4,5,7$, and rocaglaol (54) exhibited strong activities, whereas rocagloic acid (1) itself and $3^{\prime}$-hydroxyaglafoline (7) were found to be selectively toxic only against the NCI-H187 cell line (Chumkaew et al. 2006).

Another effect of functional group variation was observed by the fusion of a pyrimidinone moiety to $C$ 2 and $C-1$. The cell growth inhibiting activity was first reported for aglaiastatin (65) and dehydroaglaiastatin (66) against Ki-ras-transformed NRK cells (Ohse et al. 1996), and later for 66 and aglaiformosanin (68) against five different cancer cell lines (Wang and Duh 2001). Analysis of the cytostatic effects and the underlying mechanisms of action of six benzofurans against the colorectal carcinoma cells SW480 and HT29/HI has shown, that all derivatives caused massive, concentration-dependent cell loss in both cell lines with the pyrimidinone aglaiastatin $(\mathbf{6 5})$ as the strongest inhibitor. Compound $\mathbf{6 5}$ was found to induce growth inhibition by blocking cell cycle progression in the mitotic prophase and induce apoptosis. This study described for the first time the selective cytotoxicity of flavaglines, being highly specific for malignant cells, while normal and premalignant cells were shown to be 1.000-fold less sensitive (Hausott et al. 2004).

In a later investigation the $\mathrm{CHCl}_{3}$ extract of $\mathrm{A}$. perviridis Hiern was found to exhibit high cytotoxic activity against human colon cancer (H-29) cells (Pan et al. 2013). From ten benzofuran flavaglines seven exhibited pronounced activity with $\mathrm{ED}_{50}$ values ranging from 0.0007 to $0.056 \mu \mathrm{mol}$ with rocaglaol (54) as the most potent compound. In accord with previous findings (Bohnenstengel et al. 1999b), derivatives with the $C$-8b hydroxy group replaced by a methoxy group, including the newly described compounds 21 and 62 , were found to be much less potently cytotoxic. Interestingly, perviridisin B (107), a flavagline with a benzopyran structure, exhibited significant cytoxicity ( $\left.\mathrm{ED}_{50} 0.46 \mu \mathrm{mol}\right)$ against HT-29 cells, while the $C-10$ epimer, perviridisin A (106), was inactive in the same assay. In order to evaluate the selectivity of these potent agents for a tumorigenic cell line, compounds with $\mathrm{ED}_{50}$ values of less than $10 \mu \mathrm{mol}$ against HT-29 cells were further tested against the CCD-112CoN normal colon cell line. None of the compounds tested were found to show inhibitory activity against the normal cells at the relatively high concentration of $50 \mu \mathrm{mol}$ (Pan et al. 2013). The important role of a free $O H$ group at $C-8 \mathrm{~b}$ for cytotoxic activity was also confirmed in a 
phytochemical investigation of the twigs of $A$. odorata var. microphyllina. From five rocaglamide-type flavaglines tested against the human myeloid leukemia cell line (K562), only 3'-hyroxy-8b-methoxy-rocaglamide (29) and 8b-methoxy-desmethylrocaglamid (34) were inactive, while the other three derivatives showed pronounced cytotoxicity (Liu et al. 2013). A re-examination of the cytotoxic effects of rocaglaol (54) and rocaglamide (25) against five tumor cell lines exhibited $\mathrm{IC}_{50}$ values from 0.007 to $0.095 \mu \mathrm{mol}$ with rocaglamide (25) as the most potent inhibitor (Liu and Xu 2016).

Silvestrol as lead structure with high cytotoxic potency

An important structural modification with very high cytotoxic potency was found in silvestrol (14) and its $5^{\prime \prime \prime} \mathrm{S}$ epimer episilvestrol (15), two benzofuran flavaglines with an unusual dioxanyloxy unit attached to $C-6$ of the aromatic ring A. They were isolated and identified from the fruits and twigs of A. foveolata $\mathrm{C}$. M. Pannell (published as A. silvestris (M. Roemer) Merrill), and were found to possess comparable cytotoxic potencies for the cancer cell lines Lu1, LNCaP, and MCF-7 to those of the well-known natural anticancer compounds paclitaxel (Taxol) and camptothecin (Fig. 5). Silvestrol (14) was further evaluated as being active in vivo in the hollow fiber assay and in the murine P-388 leukemia model (Hwang et al. 2004). The evaluation of the mechanism of cytotoxicity in LNCaP cells has shown that the activity is associated with cell cycle arrest at the $G_{2} / M$ checkpoint and alterations in the expression of genes regulating apoptosis and cell cycle independent of tumor suppressor protein p53 activity (Mi et al. 2006b). A follow-up study demonstrated the involvement of the apoptosome/mitochondrial pathway and suggested the possibility that silvestrol (14) may also trigger the extrinsic pathway of programmed cell death signaling in tumor cells (Kim et al. 2007). Further experiments exhibited a dual targeting of compound $\mathbf{1 4}$ in mantle cell lymphoma with the cyclin/CDK/Rb pathway, a conserved mechanism controlling cell cycle progression, and the mitochondrial (intrinsic) pathway of apoptosis (Alinari et al. 2012). Silvestrol (14) also showed potential for the development as new therapeutic agent for B-cell malignancies including chronic lymphocytic leukemia (CLL). It exhibited a $\mathrm{LC}_{50}$ value of $7 \mathrm{nmol}$ in CLL, being more potent against B-cells than T-cells, and significantly prolonged survival in a murine model of $B$ cell acute lymphoblastic leukemia (ALL) (Lucas et al. 2009, 2010). However, a resistance to compound 14 was observed in ALL mediated by the multidrugresistant (MDR1) gene, and its product P-gp (permeability glycoprotein) overexpression (Gupta et al. 2011). In another paper the authors described the pharmacokinetic properties of $\mathbf{1 4}$ in mice, using liquid chromatography/tandem mass spectroscopy (LC-MS/ MS). They found that intraperitoneal systemic availability was $100 \%$, but oral administration resulted in only $1.7 \%$ bioavailability (Saradhi et al. 2011). A synergistic effect of silvestrol (14) in combination with other therapeutic agents was reported for the inhibition of cell growth in four different hepatocellular cancer (Kogure et al. 2013). In acute myeloid leukemia (AML), one of the most common types of leukemia, silvestrol (14) was shown to exhibit significant in vivo and in vitro activities through a novel mechanism resulting in inhibition of FLT3 (FMS-like tyrosine kinase receptor-3) and miR-155 (microRNA) expression (Alachkar et al. 2013). In in vitro and in vivo models of Epstein-Barr virus-driven lymphoproliferative diseases (EBV-LPD) silvestrol was shown to promote anti-tumor activity and simultaneously preserve the anti-tumor function of innate immune effectors (Patton et al. 2014). A study of Callahan et al. (2014) demonstrated that rocaglamide (25) and silvestrol (14) are able to preferentially kill functionally defined leukemia stem cells, while sparing normal stem and progenitor cells. In addition to efficacy as single agents, both flavaglines were shown to sensitize leukemia cells to several anticancer compounds. Compound $\mathbf{1 4}$ was also reported to potently inhibit growth of melanoma cells and induce cell death through induction of early autophagy and caspase-mediated apoptosis (Chen et al. 2016) (Fig. 5). Synergistic effects of compounds 14 and $\mathbf{1 5}$ in combination with cisplatin were observed in the inhibition of nasopharyngeal carcinoma cell proliferation (Daker et al. 2016). Recently, both silvestrols $(\mathbf{1 4}, \mathbf{1 5})$ were also isolated from the stems of $A$. stellatopilosa Pannell and their strong cytotoxicity was confirmed against the cancer cell lines H-29, MCF-7, and NCI-H460 (Othman et al. 2016). 
Structural variation of silvestrol

Interestingly, epimerization in the dioxanyloxy group of the silvestrols $\mathbf{1 4}$ and $\mathbf{1 5}$ leads to a dramatic decrease of cytotoxicity evaluated against the HT-29 human colon cancer cell line. While compounds 14 and 15 exhibited very high $\mathrm{ED}_{50}$ values of 0.0007 and $0.001 \mu \mathrm{mol}$, respectively, the two C- $2^{\prime \prime \prime}$ epimers, $2^{\prime \prime \prime}$ episilvestrol (16a) and 2"', $5^{\prime \prime \prime}$-diepisilvestrol (16b), were found to be much less active, with 2.29 and $1.07 \mu \mathrm{mol}$ (Pan et al. 2010). On the other hand, acetylation of the $\mathrm{OH}$ group at $C-6^{\prime \prime \prime}$ of the dioxanyloxy unit in aglapervirisin A (17) retained significant cytotoxicity in four human tumor cell lines, with $\mathrm{IC}_{50}$ values between 0.008 and $0.015 \mu \mathrm{mol}$. Compound $\mathbf{1 7}$ induced cell cycle arrest in the G2/M-phase in Hep G2 (liver cancer) cells at concentration of $0.010 \mu \mathrm{mol}$, and induced apoptosis at $0.160 \mu \mathrm{mol}$ (An et al. 2016).

In continuous efforts to discover new silvestrol derivatives with antineoplastic activity six new analogues (41-46) were recently isolated from the root extract of $A$. perviridis Hiern, where in all compounds the ester group at $\mathrm{C}-2$ is replaced by a $\mathrm{CONH}_{2}$ substitiuent. Apart from this amide group, two derivatives $(\mathbf{4 1}, \mathbf{4 2})$ differ from silvestrol (14) by a free $\mathrm{OH}$ group at $\mathrm{C}-2^{\prime \prime \prime}$ of the dioxanyloxy unit, while the four other derivatives (43-46) deviate by an unprecedented carbon skeleton with a dihydrofuran ring fused to the dioxanyloxy and the aromatic ring A. All compounds were evaluated for their cytotoxic activity against the HT-29 human colon cancer and PC-3 prostate cancer cell lines. The latter four compounds (43-46) were shown to be inactive $\left(\mathrm{IC}_{50}>10 \mu \mathrm{mol}\right)$ probably caused by the rigidity of the dioxanyl ring due to the fused dihydrobenzofuran ring system. The moderate activity of compound $\mathbf{4 1}$ $\left(\mathrm{IC}_{50}>2.3 \mu \mathrm{mol}\right)$ compared to silvestrol (14) could be ascribed to either or both the $O H$ group at $C-2^{\prime \prime \prime}$ or the amide group at $C-2$ (Agarwal et al. 2019).

Inhibition of the translation initiation factor (eIF) $4 \mathrm{~A}$

The level of interest in the therapeutic potential of flavaglines has been intensified by uncovering their role as direct inhibitors of translation initiation, a key process in protein synthesis (Silvera et al. 2010; Schatz et al. 2011; Bhat et al. 2015; Pelletier et al. 2015; Chu and Pelletier 2015; Chu et al. 2016a; Taylor et al.
2020; Hao et al. 2020). Pelletier's group first demonstrated that the eukaryotic initiation factor (eIF) 4A was the likely target of flavaglines. The helicase eIF4A is known to unwind secondary structures at the $5^{\prime}$-UTRs (untranslated regions) of mRNA to enable binding of the ribosomal pre-initiation complex. The authors used biochemical assays to show that 1-Oformylaglafoline (5) and silvestrol (14) stimulated an abnormal interaction of eIF4A with mRNA and prevented successful assembly of the mRNA/eIF4A dimer with the eIF4F translaton initiation complex. It was also shown that silvestrol can re-sensitize tumor cells to standard-of-care agents, such as doxorubicin, in a lymphoma model (Bordeleau et al. 2008). In following experiments it was shown that targeting the eIF4A subunit of eIF4F in human cancer xenograft tissues is sufficient to reduce tumor cell proliferation and that silvestrol (14) was the most active derivative from twelve benzofurans tested. The authors provided a mechanistic insight into the mode of action of compound $\mathbf{1 4}$ and indicated that it is a potent anticancer compound in vivo by affecting survival pathways as well as angiogenesis and appears to be well tolerated in animals (Cencic et al. 2009, 2010). To determine unequivocally the protein targets of silvestrol (14) and biotinylated episilvestrol (15) Rizzacasa's group demonstrated for the first time their direct interaction with eIF4AI and eIF4AII (Chambers et al. 2013). In a second publication they showed that aglafoline (4) and rocaglamide (25) also bind specifically to eIF4AI/II but not to prohibitins (PHB), the helicase DDX3 and eIF4E (Chambers et al. 2016). This discovery was substantiated by chemogenomic profiling to validate eIF4A as the main target of flavaglines in yeast. Here, the binding site of flavaglines could be identified by means of mutagenesis and in silico modeling (Sadlish et al. 2013). Using a series of biochemical assays and CRISPR (clustered regularly interspaced short palindromic repeats)/Cas9 genome editing, Chu et al. (2016b) provided genetic evidence that the antineoplastic activities of flavaglines are a consequence of eIF4A1 inhibition. Iwasaki et al. (2016) have shown that rocaglamide (25) induces ATP-independent "clamping" of eIF4A onto polypurine sequences in the $5^{\prime}$-cap-UTR of mRNAs, creating an inihibitory roadblock for the scanning ribosome. Structural elucidation of a rocaglamide (25)/eIF4A1/polypurine RNA complex revealed that 25 functions as interfacial inhibitor and makes critical 
contacts with eIF4A1 (F163, Q195) and two adjacent RNA purine bases (Iwasaki et al. 2019). In a more recent investigation Iwasaki's group found that the translation inhibitor rocaglamide (25) alternatively targets the helicase DDX3 in addition to eIF4A (Chen et al. 2021). This is contrary to the results of Chambers et al. (2016). Inhibition of eIF4A by silvestrol (14) was recently also shown to sensitize T-47D breast cancer cells to radiotherapy with minimal effects on unirradiated cells (Webb et al. 2020). In a screen of $>200$ flavaglines (= rocaglates) a series of potent synthetic amidino-flavaglines was identified (e.g. CMLD012612, Fig. 6). They were shown to target eIF4A1 and eIF4A2, to potently inhibit translation and tumor cell viability, and are effective in synergizing with DNA-damaging agents in vivo against the MYC (proto-oncogene)-driven lymphomas (Chu et al. 2019). Despite showing promising anticancer activities, the development of flavagline derivatives as therapeutic agents has been hampered because of poor drug-like properties and synthetic complexity. Utilizing a ligand-based design strategy to optimize physicochemical properties and mechanistic studies to further elucidate mRNA sequence selectivity, key regulated target genes, and the associated antitumor phenotype, the synthetic flavagline eFT226 was designed. This compound, also named zotatifin, showed excellent physicochemical properties and significant antitumor activity and is already under clinical investigation (Ernst et al. 2020).

Prohibitins (PHB)-1 and 2 as targets of flavaglines

Two conflicting reports have been published concerning the protein targets. Li-Weber and colleagues at the German Cancer Research Center (DKFZ) have demonstrated that several benzofuran flavaglines prevent tumor growth and sensitize resistant cancer cells to apoptosis by blocking the Raf-MEK (mitogen and extracellular-signal regulated protein kinase)ERK (extracellular-signal regulated protein kinase) signaling pathway. However, the molecular target of flavaglines in this pathway remained unknown (Zhu et al. 2007; Bleumink et al. 2011). In a following study, using an affinity chromatography approach, it was found that prohibitins (PHB)-1 and 2 are the direct targets of flavaglines (Polier et al. 2012) and it was therefore concluded that flavagline binding to PHB prevented it from interaction with cRaf, and thus inhibiting translation indirectly by blocking the RafMEK-ERG pathway. However, in accord with the results of Chambers et al. (2016), previous work suggested that PHB 1/2 are not likely to be involved in the mode of action of translation inhibition as flavaglines have retained translational activity in cellular extracts, which do not have a functional RafMEK-ERG pathway, which is responsible for communication between extracellular receptor and the nucleus (Bordeleau et al. 2008). The synthetic flavagline FL3 (Fig. 6), was shown to directly target PHB and inhibits UCB (urothelial carcinoma of the bladder) cell proliferation both in vitro and in vivo (Yuan et al. 2018). As PHB proteins are involved in regulation of several important signaling pathways in different cellular compartments (Thuaud et al. 2013), it was suggested that flavaglines may serve as a new smallmolecular tool for studying PHB-mediated cellular processes (Bentayeb et al. 2019). In a more recent study PHB2 was identified to mediate mitophagy, a conserved cellular process for selectively removing damaged or unwanted mitochondria. It was found that the synthetic flavagline FL3 inhibits PHB2-mediated mitophagy and blocks cancer cell growth at nanomolar cocentrations (Yan et al. 2020).

\section{Targeting the transcriptional factor HSF1}

The transcriptional factor HSF1 (heat shock factor 1) is deeply involved in metabolic programming, survival, and proliferation of cancer cells in addition to heat-shock response. To shed light on how the inhibition of protein synthesis selectively impedes the proliferation of cancer cells without effecting normal cells more than 300,000 compounds were screened for the inhibition of the transcriptional factor HSF1. Among these compounds rocaglamide (25) was found to be the most potent and selective inhibitor of HSF1 signaling $\left(\mathrm{IC}_{50} \sim 50 \mathrm{nmol}\right)$. Five synthetic hydroxam analogues showed even more activity with rohinitib (Fig. 6) as the strongest inhibitor $\left(\mathrm{IC}_{50-}\right.$ $\sim 20 \mathrm{nmol}$ ) (Santagata et al. 2013).

\section{Antiviral activities}

Since the replication of several viruses relies on the host translation system, a dependence on the initiation factor eIF4A for their translation by the host protein synthesis was to be expected. Inspired by the role of 
flavaglines as direct inhibitors of translation initiation Grünweller and colleagues investigated the inhibiting effect of silvestrol (14) on the replication of Ebola virus (EBOV), a negative-stranded RNA virus. Silvestrol was known to exert potent antitumor activity by inhibiting translation of short-lived onco-proteins (Lucas et al. 2009; Kogure et al. 2013), whose mRNA contains extended $5^{\prime}$-cap-UTRs (untranslated regions) and includes regions of stable RNA secondary structures that require unwinding by the helicase eIF4A. Since the mRNAs of EBOV adopt stable RNA secondary structures in their UTRs, a corresponding mechanism was assumed. The authors observed that silvestrol (14) inhibited an infection of EBOV in human macrophages at low nanomolar concentrations, and effective silvestrol concentrations were non-toxic in the tested cell systems (Biedenkopf et al. 2017). Many plus-stranded RNA viruses, such as corona virus $(\mathrm{CoV})$ and the picornaviruses human rhinovirus A1 (HRV A1) and poliovirus typ1 (PV), carry long and highly structured $5^{\prime}$-cap-UTRs with important functions in viral replication and/or translation initiation. Using a dual luciferase assay and virus-infected primary cells, Müller et al. (2018) found that silvestrol (14) is also a potent inhibitor of cap-dependent viral mRNA translation in $\mathrm{CoV}$-infected human embryonic lung fibroblast (MRC-5) cells. High $\mathrm{EC}_{50}$ values at $1.3 \mathrm{nmol}$ and $3.0 \mathrm{nmol}$ silvestrol were determined for MERS-CoV (Middle East Respiratory Syndrome coronavirus) and HCoV-229E (human coronavirus 229E), respectively. For the highly pathogenic MERS$\mathrm{CoV}$, the potent antiviral activity of compound $\mathbf{1 4}$ was alo confirmed using peripheral blood mononuclear cells as a second type of human primary cells. It was shown that silvestrol strongly inhibits the expression of $\mathrm{CoV}$ structural and nonstructural proteins and the formation of viral replication/transcription complexes. Furthermore, antiviral effects of $\mathbf{1 4}$ against HRV A1 and PV were also investigated. Both viruses employ an Internal Ribosomal Entry Site (IRES)-mediated translation initiation mechanism. For PV, which is known to require the activity of eIF4A, an $\mathrm{EC}_{50}$ value at $20 \mathrm{nmol}$ silvestrol (14) was determined in MRC-5 cells. The higher value at $100 \mathrm{nmol}$ measured for HRV A1 indicated a less critical role of eIF4A activity in HRV A1 IRES-mediated translation initiation (Müller et al. 2018).

A series of following investigations confirmed the antiviral properties of flavaglines and contributed to a deeper understanding of the mode of action. Silvestrol (14) was also shown to inhibit the replication of HEV (hepatitis E virus), and was evaluated for its specific inhibition of eIF4A in different HEV experimental model systems including HEV primary isolates and $\mathrm{HEV}$-infected humanized mice. It was demonstrated that silvestrol blocks replication of different subgenomic replicons in a dose-dependent manner at low nanomolar concentrations. Moreover, a combined treatment of viral infection with ribavirin, a nucleosid inhibitor, revealed an additive effect (Todt et al. 2018). In another study the impact of silvestrol (14) on the $\mathrm{HEV}$ life cycle was analyzed. It was found that $\mathbf{1 4}$ is a potent inhibitor of the release of HEV infectious viral particles, and that this effect goes along with a strongly reduced $\mathrm{HEV}$ capsid protein translation, retention of viral RNA inside the cytoplasm, and without major cytotoxicity (Glitscher et al. 2018). Silvestrol (14) was also active against two strains of ZIKV (Zika virus) using lung adenocarcinoma (A549) cells and primary human hepatocytes (PHH). However, the results showed that the silvestrol-dependent effects on the ZIKV life cycle did not follow a strict dose-effect relation in A549 cells. While $5 \mathrm{nmol}$ and $50 \mathrm{nmol}$ silvestrol exerted a strong inhibition of ZIKV replication, $10 \mathrm{nmol}$ failed to impair replication most likely due to secondary effects in the infected host cell (Elgner et al. 2018). The antiviral activity of silvestrol (14) was also reported for CHIKV (chikungunya virus), a positive single-stranded RNA virus (Henss et al. 2018). Interesting results were obtained by comparing the broad-spectrum antiviral activities of the eIF4A inhibitor silvestrol with those of the synthetic amidino-flavagline CR-1-31-B (Fig. 6), lacking the dioxane moiety of silvestrol. Even though similar antiviral activities were found for this less complex structured flavagline in different viruses, substantial mechanistic differences were observed. RNA clamping with CR-1-131-B depends on a polypurine stretch in the bound RNA substrate whereas silvestrol (14) with its dioxanyloxy moiety can also clamp RNA onto eIF4A without a strict requirement for a polypurine stretch in the RNA substrate (Müller et al. 2020). In a following paper Müller et al. (2021) assessed the antiviral activity of CR-1-131-B against SARS-CoV-2 using both in vitro and ex vivo cell culture models. In Vero E6 cells it inhibited SARS-CoV-2 replication with an $\mathrm{EC}_{50}$ of $\sim 1.8 \mathrm{nmol}$. In primary human airway epithelial 
cells CR-1-131-B reduced viral titers to undetectable levels at a concentration of $100 \mathrm{nmol}$. Reduced virus reproduction was accompanied by substantially reduced viral protein accumulation and replication/transcription complex formation. Taken together, the data available so far characterize the complex antiviral activity of flavaglins and show their broad spectrum of functions (Fig. 5). As recently highlighted by Schulz et al. (2021) flavaglines are not only promising anticancer agents but gained now also high expectations as agents against emerging RNA viruses like SARS-CoV-2. This was outlined in a more recent review by Taroncher-Oldenburg et al. (2021), where they described the targeting of the helicase eIF4A with flavaglines as a pan-antiviral strategy for minimizing the impact of future RNA virus pandemics.

Antiprotozoal activities

In a preliminary screening for biologically active constituents the ethanol extract of the seeds of A.erythrosperma C. M. Pannell exhibited significant antimalarial activity. In a microculture radioisotope assay against a multidrug resistant strain (K1) of the malarial parasite Plasmodium falciparum, the benzofuran flavagline $4^{\prime}$-demethoxy- $3^{\prime}, 4^{\prime}$-methylenedioxyaglafoline (18) was shown to be responsible for the anti-plasmodial activity with an $\mathrm{IC}_{50}$ value of $7.30 \mu \mathrm{g} / \mathrm{ml}$ (Phongmaykin et al. 2011). In the course of investigating the anti-leishmanial activity of 13 plant-derived compounds against Leishmania infantum promastigotes in vitro, the benzofurans aglafoline (4) and rocaglamide (25) showed promising potencies with $50 \%$ effective concentrations $\left(\mathrm{EC}_{50}\right)$ of 7.45 and $16.45 \mu \mathrm{mol}$, respectively, after $24 \mathrm{~h}$ of exposure (Astelbauer et al. 2011). In a follow-up study these two flavaglines were also tested for their antiplasmodial activity in vitro. In this case, fresh Plasmodium falciparum isolates were taken from patients in the area of Mae Sot in NW Thailand and the inhibition of schizont maturation was determined. With $\mathrm{IC}_{50}$ values of $53.49 \mathrm{nmol}$ for aglafoline (4) and $60.59 \mathrm{nmol}$ for rocaglamide (25) the activities were significantly below that of artemisinin, but moderately higher than that of quinine (Astelbauer et al. 2012). In continuation of this screening program for antiprotozoal activities aglafoline (4) also showed pronounced activity against Giardia duodenalis trophozoites colonizing the small intestine. The $\mathrm{EC}_{50}$ values after $24 \mathrm{~h}$ and $48 \mathrm{~h}$ were $17.2 \mu \mathrm{mol}$ and $7.71 \mu \mathrm{mol}$, respectively (Drinić et al. 2019).

In the treatment of malaria recent studies have pointed to initiation of protein synthesis as a novel pharmacological target. Considering the role of flavaglines as inhibitors of protein synthesis by targeting the translation initiation factor eIF4A, the synthetic flavagline CR-1-31-B (Fig. 6) was tested for inhibitory effects in Plasmodium parasites. It was found that this compound perturbs association of Plasmodium falciparum eIF4A (PfeIF4A) with RNA. It showed potent prophylactic and therapeutic antiplasmodial activity in vivo in mouse models of infection with $P$. berghei (cerebral malaria) and $P$. chabaudi (blood-stage malaria) and can also block replication of different clinical isolates of $P$. falciparum in human erythrocytes, including drug-resistant isolates (Langlais et al. 2018).

\section{Anti-inflammatory activities}

The anti-inflammatory properties of crude extracts of different Aglaia species were supposed to be mediated by the transcription factor NF- $\kappa \mathrm{B}$, which plays a key role in regulating the immune response to infection. Baumann et al. (2002) tested sixteen benzofuran flavaglines and one benzopyran flavagline for their ability to inhibit NF- $\kappa \mathrm{B}$ activity. The three benzofuranes didesmethylrocaglamide (38), desmethylrocaglamide (32) and rocaglamide (25) showed a dose-dependent inhibition of PMA (phorbol myristate acetate)- and TNF (tumor necrosis factor)-induced $\mathrm{NF}-\kappa \mathrm{B}$ activation in Jurkat $\mathrm{T}$ cells, and mediated an almost complete inhibition at a final concentration of 200 nmol. Compound $\mathbf{3 8}$ was found to be the most active $\mathrm{NF}-\kappa \mathrm{B}$-specific derivative with $\mathrm{IC}_{50}$ values at $58 \mathrm{nmol}$ for TNF- and $44 \mathrm{nmol}$ for PMA-induced activity. A replacement of the amide group at $C-2$ by $C O O \mathrm{Me}$ or by $C-2$ unsubstituted derivatives as well as the insertion of a hydroxy or methoxy group in $C-3^{\prime}$ led to a reduction of $\mathrm{NF}-\kappa \mathrm{B}$ inhibitory potential. A decrease of activity was also observed by an introduction of either a $3^{\prime}, 4^{\prime}$ - or 6,7-methylenedioxy group. However, the most dramatic loss in NF- $\mathrm{KB}$ inhibition was observed by replacing the $O H$ group at $C-8 \mathrm{~b}$ by a methoxy group. Also, the replacement of the benzofuran backbone by a benzopyran skeleton led to a total loss of activity (Baumann et al. 2002). It is interesting 
to note that these results correspond well with those of findings mentioned above, where insecticidal properties and antiproliferative activities were determined (Bohnenstengel et al. 1999b). In a search for anticancer agents ten benzofuran flavaglines, isolated from A. perviridis, were also evaluated for their NF$\kappa \mathrm{B}$ (p65) inhibitory activity. With an $\mathrm{ED}_{50}$ value of $0.005 \mu \mathrm{mol}$ rocaglaol (54) was extremly active, being 10 times more potent than the control compound rocaglamide (25) (Pan et al. 2013).

Li-Weber and colleagues showed that flavaglines are potent immunosuppressive compounds that suppress the production of several cytokines in peripheral blood T-cells at nanomolar concentrations. They also found that the doses that inhibit cytokine production, selectively inhibit the activity of NF-AT (Nulclear Factor of Activated T-cells) without impairing the activities of the transcription factors NF- $\kappa \mathrm{B}$ and AP-1 (Activator Protein-1) (Proksch et al. 2005). A synthetic monofluor derivative of rocaglaol (54) displayed potent anti-inflammatory properties in human endothelial and murine glial cells in vitro. It was identified as a potent inhibitor of cytokine-mediated signaling and showed neuroprotective activity in vitro and in animal models of Parkinson 's disease and traumatic brain injury (Fahrig et al. 2005). In an enzyme-based ELISA assay the newly described benzopyran flavagline ponapensin (133), isolated from the leaves and stems of $A$. mariannensis Merrill (=A. ponapensis Kanehira), was shown to exhibit significant $\mathrm{NF}-\kappa \mathrm{B}$ inhibitory activity. With an $\mathrm{IC}_{50}$ value of $0.06 \mu \mathrm{mol}$ it was more potent than the two benzofuran flavaglines rocaglamide (25) and aglafoline (4), with values of 2.0 and $2.3 \mu \mathrm{mol}$. The other benzopyrans $(\mathbf{7 8}, \mathbf{7 9}, \mathbf{8 0}, \mathbf{8 5})$, isolated in this study, were not active ( $\mathrm{IC}_{50}>5 \mu \mathrm{mol}$ ) (Salim et al. 2007b). In a more recent study the immunomodulatory effects of silvestrol (14) on human monocyte-derived macrophages and dendritic cells was investigated. Compound 14 was shown to down-regulate several proand anti-inflammatory cytokines and increased TNF- $\alpha$ during differentiation and activation of M1-macrophages, suggesting that the effects of silvestrol might cancel each other out. However, silvestrol (14) amplified the anti-inflammatory potential of M2macrophages by increasing expression of anti-inflammatory surface markers (CD206, TREM2) and reducing release of pro-inflammatory cytokines (IL8, CCL2). The results showed that silvestrol (14) influences the inflammatory status of immune cells depending on the cell type and activation status (Blum et al. 2020).

\section{Antifungal activities}

In a routine screening for antifungal properties the dichloromethane extract of the stem bark of $A$. elaeagnoidea showed activity against Cladosporium cucumerinum in a TLC bioassay. Activity-guided fractionation led to the isolation of aglafoline (4) which inhibited the growth of the fungus at $2.5 \mu \mathrm{g}$ (Fuzzati et al. 1996). Using the spore germination inhibition assay in microwells, eight flavaglines, isolated from A.odorata, A. elaeagnoidea and A.edulis, were tested against the three plant pathogenic fungi, Pyricularia grisea, Alternaria citri, and Fusarium avenaceum. Based on digital image analysis of germ tubes, six benzofuran flavaglines showed clear antifungal activities, whereas a benzopyran and a benzoxepine flavagline were inactive. High activities were observed especially against Pyricularia grisea, the causative fungus of rice blast disease, with MIC values of $1.6 \mu \mathrm{g} / \mathrm{ml}$ for rocaglaol (54), $3 \mu \mathrm{g} / \mathrm{ml}$ for aglafoline (4), and $25 \mu \mathrm{g} / \mathrm{ml}$ for rocaglamide (25). Lower values were determined for pannellin (22) with $50 \mu \mathrm{g} / \mathrm{ml}$, and for aglaroxin A (47) and desmethylrocaglamide (32) with $100 \mu \mathrm{g} / \mathrm{ml}$ each (Engelmeier et al. 2000). The lipophilic crude extracts from different Aglaia species were also tested for their effectiveness of growth inhibition against postharvest pathogenes. Bioassay-guided fractionation led to the isolation of the benzofuran flavaglines aglafoline (4), didesmethylrocaglamide (38), and rocaglaol (54), which exhibited significant antifungal activities against three different microfungi. The highest activities were determined for rocaglaol (54) with an $\mathrm{EC}_{50}$ value at $0.05 \mu \mathrm{g} / \mathrm{ml}$ against Pestalotiopsis sp., followed by $1.2 \mu \mathrm{g} / \mathrm{ml}$ against Botrytis cinerea, and $52 \mu \mathrm{g} / \mathrm{ml}$ against Colletrotrichum gloeosporioides (Khewkhom et al. 2006). Silvestrol (14) and episilvestrol (15) exhibited growth inhibition activity of $>$ 90\% against the two yeasts Saccharomyces cerevisiae and Rhodoturula glutinis, at a concentration of $200 \mu \mathrm{mol}$ (Othman et al. 2016). In a more recent investigation it was found that a group of synthetic flavaglines activates a species-specific cell death program by translation inhibition in the emerging fungal pathogen Candida auris (Iyer et al. 2020). 
Miscellaneous properties

The platelet-activating factor (PAF), a phospholipid mediator, plays an important role in inflammatory response and mediation. In the search for specific PAF antagonists Ko et al. (1992) found that aglafoline (4), isolated from A. rimosa, selectively inhibited PAFinduced platelet aggregation in washed rabbit platelets in a concentration-dependent manner. In a following study the coexisting rocaglamide (25) was also tested for inhibition of platelet aggregation induced by adenoside diphosphate (ADP), arachidonic acid (AA), PAF, and collagen. It was shown that $100 \mu \mathrm{g} /$ $\mathrm{ml}$ of aglafoline (4) completely blocked the platelet aggregation caused by PAF and AA but had no effect on that caused by ADP or collagen, while rocaglamide (25) were either completely inactive or showed only slight inhibition at the doses tested (Wu et al. 1997).

The leaf extract of $A$. forbesii was tested for antimycobacterial activity. From three benzopyran flavaglines isolated, isofoveoglin (= desacetylpyramidaglain D) (111) exhibited the highest activity against Mycobacterium tuberculosis with a MIC-value at $25 \mu \mathrm{g} / \mathrm{ml}$ which was compared with the two positive controls kanamycin with $1.25 \mu \mathrm{g} / \mathrm{ml}$ and isoniazid with $0.25 \mu \mathrm{g} / \mathrm{ml}$ (Joycharat et al. 2008a). Moderate anti-mycobacterial activity with a MIC-value at $50 \mu \mathrm{g} / \mathrm{ml}$ was also reported for the benzofuran $4^{\prime}$ demethoxy- $3^{\prime}, 4^{\prime}$-methylenedioxyaglafoline (18) from the seed extract of $A$. erythrosperma. The activity was assayed in duplicate, using the Alamar blue test, and MIC-values below $200 \mu \mathrm{g} / \mathrm{ml}$ were considered active (Phongmaykin et al. 2011).

\section{Chemotaxonomic significance}

The formation of flavaglines represents a unique chemical character of the genus Aglaia comprising around 120 species. Together with the characteristic indumentum of stellate hairs or peltate scales it distinguishes Aglaia from the other genera in the family Meliaceae. However, as some species are very similar in their morphology, taxonomic identification of the genus to the level of the species turned out to be difficult. Even the most indicative morphological characters vary considerably, so that Pannell (1992, 1994) adopted a wide species concept. Mainly based on fruit characters the genus is divided into the section Amoora with dehiscent, and section Aglaia with indehiscent fruits. The third section Neoaglaia was later proposed for species with dehiscent fruits but with flower characters intermediate between Amoora and Aglaia. A broad-based UV-HPLC comparison of crude extracts of 30 different Aglaia species has shown that flavaglines are widespread in both sections Aglaia and Amoora, but could not be detected so far in different accessions of $A$. lawii (Wight) Saldanha and A. teysmanniana (Miq.) Miq., mainly constituting the section Neoaglaia. Preliminary work combining into a systematic framework data from morphological characters, DNA analysis and phytochemicals has already been published (Muellner et al. 2005, 2009).

The UV-HPLC profiles of crude extracts of the widespread and morphologically variable A. elaeagnoidea (A. Juss.) Benth. were compared in our laboratory to assess the wide species concept proposed by Pannell (1992). Identification of the major flavaglines revealed a dominating 8-methoxy-6,7-methylenedioxy substitution in ring $\mathrm{A}$. This biogenetic trend was also found in a large-scale collection $(500 \mathrm{~kg})$ of the stem bark of A. elaeagnoidea (syn.: A. roxburghiana), collected in Sri Lanka, where it was detected in a series of derivatives with the two benzofurans aglaroxin A (47) and aglaroxin $C$ (72) as major constituents (Molleyres et al. 1999). The same substructure of ring A was found to prevail in different geographical provenances of A. elaeagnoidea from Bangladesh, Thailand, and Vietnam (Hofer 2002; Muellner et al. 2009), where it was also detected in the co-ocurring benzopyrans, benzoxepines, and flavonoids, as well as in the structurally related aglalactone (Brader et al. 1998; Bacher et al. 1999; Seger et al. 2000). In contrast, the HPLC profiles of A. elaeagnoidea collected in Australia clearly differ by flavaglines with the widespread 6,8-dimethoxylation of ring A. Based on chromatographic comparison with authentic samples the major compounds were identified as the benzofurans rocaglamide (25) and aglafoline (4) (Hofer 2002; Brem 2002). This deviating chemical profile together with differences in leaf morphology, fruit colour, and DNA data (Muellner et al. 2009), suggests a taxonomic rearrangement of the Australian accessions as a separate species.

The 8-methoxy-6,7-methylenedioxy substitution of flavaglines was also found to be typical for different collections of A. edulis (Roxb.) Wall., with aglaroxin A (47) as major compound. As shown in the stembark 
and roots of a $20 \mathrm{~m}$ tall tree, collected in southwest Thailand, compound 47 was accompanied by pannellin (22) and a series of benzopyrans (123, 129-133) and benzoxepines $(\mathbf{1 4 3}, \mathbf{1 4 5})$, all of them were characterized by the same substitution pattern of ring A (Bacher et al. 1999). This common trend was also detected in an accession from Indonesia, where in addition to aglaroxin A (47), the closely related derivatives 48 and $\mathbf{5 1}$ were isolated, together with the benzopyrans 124-128, and the benzoxepines 146-148 (Kim et al. 2005, 2006a). All these findings were in contrast to a previous report on A. edulis from southeast Thailand, where no flavaglines could be detected at all. In this case, a unique threefold acylated putrescine derived imide, edulimide (Table 2B), was isolated as the main component (Brader et al. 1998). This suggested a taxonomic segregation from $A$. edulis, also supported by a different type of indumentum showing peltate scales, instead of pale brown stellate hairs typical for A. edulis. However, according to Pannell (1992), A. edulis comprises 35 synonyms which cannot conveniently be subdivided into separate species or subspecies on present morphological characters. Since intermediate representatives are to be expected which have both hairs and scales, only further collections with flowers and fruits could come up to a final taxonomic decision. The taxonomic separation of A. edulis from A. elaeagnoidea is based on its larger leaves and much larger (edible) fruits (Pannell 1992), and is also suggested by DNA data. However, due to the variability of the leaf size, large leaved specimens from A. elaeagnoidea can sometimes be almost indistinguishable from A. edulis (Muellner et al. 2009).

Regarding the chemotaxonomic significance of the 8-methoxy-6,7-methylenedioxy substructure for $A$. elaeagnoidea and A. edulis, its formation in $A$. oligophylla Miq., collected in Vietnam (Dreyer et al. 2001; Bringmann et al. 2003), appears unusual. Even more, as other accessions of A. oligophylla, collected in Thailand, can be clearly distiguished by the constant predominance of rocaglaol (54), which structurally differs by the more widespread 6,8-dimethoxylation of ring A (Brem 2002). This predominant trend towards rocaglaol (54) in A. oligophylla was later also confirmed for another collection from south Thailand (Joycharat et al. 2008b). With respect to 6,8dimethoxylation of the dominating flavaglines 66 , 67, and 78, the Chinese A. testicularis C.Y. Wu (Wang et al. 2004a) can be chemically distinguished from $A$. edulis, where it is currently treated as a synonym (Pannell 1992).

Based on different UV-HPLC profiles of the crude extracts from the widespread A. tomentosa Teijsm. \& Binn., collected in Thailand, Malaysia, and Australia, the accessions can be clearly separated into two groups. One group is characterized by the genusspecific flavagline/bisamide profile, while the other differs by dominating lignans (Bachratá 2008). Identification of the major components revealed a predominance of rocaglaol (54) in all flavagline containing accessions (Brem 2002), while the lignan producing group is characterized by the dominating ( +)-methylarctigenin, a dibenzylbutyrolactone-type lignan (Brader et al. 1998; Bachratá 2008). The Australian accessions of $A$. tomentosa were exclusively characterized by flavaglines, showing a nearly identical HPLC profile to those collected in Thailand. Apart from the dominating rocaglaol (54), already published for its synonym A. ferruginea C.T. White \& Francis (Mulholland and Naidoo 1998), the profiles consisted of small amounts of non-identified flavaglines, probably pyrimidinones and benzopyrans, and bisamides (Bachratá 2008). In contrast to this uniform and widespread profile detected in Thailand and Australia, the lignan-containing accessions from Thailand indicated affinities to A. cordata Hiern, where structurally similar aryltetrahydronaphthalene lignans were isolated (Wang et al. 2001b, 2002, 2004b). These findings would suggest a segregation of $A$. cordata from A. tomentosa, where it is currently treated either as a synonym (Pannell 1992) or subspecies (Pannell 1994). Regarding the chemical affinity of $A$. tomentosa to other members of the A. tomentosa group, comprising 13 species, $A$. exstipulata (Griffith) Theobald appears to be the nearest relative. Many accessions of this species collected in Thailand exhibited a constant flavagline pattern with rocaglaol (54) as dominating compound. By contrast, A. archboldiana A.C. Smith and $A$. tenuicaulis Hiern, two other members of the $A$. tomentosa group, clearly differ by lacking flavaglines. Instead, sesamin-type lignans were isolated from the former (Bachratá 2008), and sulfur-containing bisamides and related amide-esters from the latter species (Greger et al. 2008).

In spite of the fragmentary reports on flavaglines of the section Amoora, some general chemical trends 
became apparent. In contrast to section Aglaia the benzofurans were shown to be devoid of nitrogen and were mainly characterized by a $3^{\prime}, 4^{\prime}$-methylenedioxy substitution of ring $B$. The pronounced formation of $4^{\prime}$-demethoxy- $3^{\prime}, 4^{\prime}$-methylenedioxyaglafoline (18) represents a characteristic chemical feature reported so far for A. spectabilis (Miq.) Jain \& Bennet (Schneider et al. 2000), A. dasyclada Miq. (Chaidir et al. 2001), A. erythrosperma C. M. Pannell (Phongmaykin et al. 2011) and A. meridionalis C. M. Pannell (Brem 2002), and is shown to be frequently accompanied by $4^{\prime}$-demethoxy- $3^{\prime}, 4^{\prime}$-methylenedioxyrocaglaol (61). Moreover, another chemical feature of the section Amoora appears to be the occurrence of the rare rocagloic acid (1) in A. cucullata (Roxb.) Pellegrin (Chumkaew et al. 2006) and A. rubiginosa (Hiern) C. M. Pannell (Rivero-Cruz et al. 2004), and the bisamide aglairubine (Table 1B). With regard to the confined distribution of this chemical profile, the coexisting $3^{\prime}, 4^{\prime}$-methylenedioxy derivatives of aglafoline $(18,19)$ and rocaglaol $(61,63)$ in A. elliptica Blume of the section Aglaia (Cui et al. 1997) was surprising and needs a re-identification of the plants. Even more, as different nitrogen-containing rocaglamide derivatives $(\mathbf{2 5}, \mathbf{3 8}, \mathbf{7 5}, \mathbf{7 6}, \mathbf{7 7})$ were published for another collection of A. elliptica (Nugroho et al. 1997b), and many further accessions from Thailand, identified by C. M. Pannell, were uniformly characterized by a lack of flavaglines. In this case, the absence of flavaglines was also confirmed by parallel bioassays of crude extracts, where no insect toxicity was determined (Brem 2002). On the other hand it should be noted, that the "Amoora-profile" with $3^{\prime}, 4^{\prime}$ methylenedioxy substitution in ring $\mathrm{B}(\mathbf{1 8}, \mathbf{1 9}, \mathbf{2 1}, \mathbf{6 1}$, 62) was also reported for an accession of A. perviridis Hiern of the section Aglaia. However, the profile differed by an additional formation of the nitrogencontaining didesmethylrocaglamide (38), and of rocaglaol (54) and aglafoline derivatives $(4,5,11)$. It might be of chemosystematic relevance, that here the new benzopyrans perviridisins $\mathrm{A}$ and $\mathrm{B}(\mathbf{1 0 6}, \mathbf{1 0 7})$ were isolated, whose bisamide moieties are characterized by aglairubine ( $P a n$ et al. 2013). In a reinvestigation of the roots of $A$. perviridis, originating from the same locality in Vietnam, the highly bioactive silvestrols 14 and 15 were isolated along with a new type of closely related derivatives (41-46). However, in contrast to the previous study no indication was given for coexisting $3^{\prime}, 4^{\prime}$-methylenedioxy substituted benzofuran derivatives (Agarwal et al. 2019). The formation of silvestrol (14) in A. perviridis was confirmed in another collection from south China, where it was isolated together with a series of benzopyrans (116-118, 121, 122), whose bisamide moieties are characterized by benzoic and phenylacetic acid moieties (An et al. 2016). Regarding the restricted occurrence of silvestrol (14), only known so far from the four species A. foveolata C. M. Pannell (Hwang et al. 2004), A. leptantha Miq. (MeurerGrimes et al. 2004), A. perviridis Hiern (An et al. 2016; Agarwal et al. 2019), and A. stellatopilosa C. M. Pannell (Othman et al. 2016), this rare structural modification of flavaglines can be expected as another chemical feature to characterize a group of related species. ${ }^{3}$

Funding Open access funding provided by University of Vienna.

Open Access This article is licensed under a Creative Commons Attribution 4.0 International License, which permits use, sharing, adaptation, distribution and reproduction in any medium or format, as long as you give appropriate credit to the original author(s) and the source, provide a link to the Creative Commons licence, and indicate if changes were made. The images or other third party material in this article are included in the article's Creative Commons licence, unless indicated otherwise in a credit line to the material. If material is not included in the article's Creative Commons licence and your intended use is not permitted by statutory regulation or exceeds the permitted use, you will need to obtain permission directly from the copyright holder. To view a copy of this licence, visit http://creativecommons.org/licenses/by/4.0/.

\section{References}

Adams TE, El Sous M, Hawkins BC, Hirner S, Holloway G, Khoo ML, Owen DJ, Savage GP, Scammells PJ, Rizzacasa MA (2009) Total synthesis of the potent anticancer Aglaia metabolites (-)-silvestrol and (-)-episilvestrol and the active analogue (-)-4'-desmethoxyepisilvestrol. J Am Chem Soc 131:1607-1616

Agarwal G, Wilson JR, Kurina SJ, Anaya-Eugenio GD, Ninh TN, Burdette JE, Soejarto DD, Cheng X, Carcache de Blanco EJ, Rakotondraibe LH, Kinghorn AD (2019) Structurally modified cyclopenta[ $b]$ benzofuran analogues isolated from Aglaia perviridis. J Nat Prod 82:2870-2877

\footnotetext{
3 After finalizing the present review, a parallel report appeared on different classes of compounds of Aglaia including flavaglines (Harneti and Supratman (2021)).
} 
Ahmed F, Toume K, Sadhu SK, Ohtsuki T, Arai MA, Ishibashi M (2010) Constituents of Amoora cucullata with TRAIL resistance-overcoming activity. Org Biomol Chem 8:3696-3703

Aktas BH, Halperin JA, Wagner G, Chorev M (2011) Inhibition of translation initiation as a novel paradigm for cancer therapy. Ann Rep Med Chem 46:189-210

Alachkar H, Santhanam R, Harb JG, Lucas DM, Oaks JJ, Hickey CJ, Pan L, Kinghorn AD, Caligiuri MA, Perrotti D, Byrd JC, Garzon R, Grever MP, Marcucci G (2013) Silvestrol exhibits significant in vivo and in vitro antileukemic activities and inhibits FLT3 and miR-155 expressions in acute myeloid leukemia. J Hematol Oncol 6:21

Alinari L, Prince CJ, Edwards RB, Towns WH, Mani R, Lehmann A, Zhang X, Jarjoura D, Pan L, Kinghorn AD, Grever MR, Baiocchi RA, Lucas DM (2012) Dual targeting of the cyclin/Rb/E2F and mitochondrial pathways in mantle cell lymphoma with the translation inhibitor silvestrol. Clin Cancer Res 18:4600-4611

An FL, Wang JS, Wang H, Wang XB, Yang MH, Guo QL, Dai Y, Luo J, Kong LY (2015) Cytotoxic flavonol-diamide $[3+2]$ adducts from the leaves of Aglaia odorata. Tetrahedron 71:2450-2457

An FL, Wang XB, Wang H, Li ZR, Yang MH, Luo J, Kong LY (2016) Cytotoxic rocaglate derivatives from leaves of Aglaia perviridis. Sci Rep 6:20045

Astelbauer F, Obwaller A, Raninger A, Brem B, Greger H, Duchêne M, Wernsdorfer W, Walochnik J (2011) Antileishmanial activity of plant-derived acridones, flavaglines and sulfur-containing amides. Vector Borne Zoonotic Dis 11:793-798

Astelbauer F, Gruber M, Brem B, Greger H, Obwaller A, Wernsdorfer G, Congpuong K, Wernsdorfer WH, Walochnik J (2012) Activity of selected phytochemicals against Plasmodium falciparum. Acta Trop 123:96-100

Bacher M, Hofer O, Brader G, Vajrodaya S, Greger H (1999) Thapsakins: possible biogenetic intermediates towards insecticidal cyclopenta[b]benzofurans from Aglaia edulis. Phytochemistry 52:253-263

Bachratá M (2008) Flavagline, Bisamide und Lignane als chemische Merkmale für eine infraspezifische Differenzierung der Aglaia tomentosa-Gruppe (Meliaceae). Master-thesis, University of Vienna

Basmadjian C, Thuraud F, Ribeiro N, Désaubry L (2013) Flavaglines: potent anticancer drugs that target prohibitins and the helicase elF4A. Future Med Chem 5:2185-2197

Basmadjian C, Zhao Q, de Gramont A, Serova M, Faivre S, Raymond E, Vagner S, Robert C, Nebigil CG, Désaubry L (2015) Bioactive flavaglines: synthesis and pharmacology. In: Brahmachari $G$ (ed) Bioactive natural products: chemistry and biology, vol 7. Wiley-VCH Verlag, New York

Baumann B, Bohnenstengel F, Siegmund D, Wajant H, Weber C, Herr I, Debatin KM, Proksch P, Wirth T (2002) Rocaglamide derivatives are potent inhibitors of NF- $\mathrm{KB}$ activation in T-cells. J Biol Chem 277:44791-44800

Bentayeb H, Aitamer M, Petit B, Dubauet L, Elderwish S, Désaubry L, de Gramont A, Raymond E, Olivrie A, Abraham J, Jauberteau MO, Troutaud D (2019) Prohibitin (PHB) expression is associated with aggressiveness in DLBCL and flavagline-mediated inhibition of cytoplasmic
PHB functions induces anti-tumor effects. J Exp Clin Cancer Res 38:450-464

Bhat M, Robichaud N, Hulea L, Sonenberg N, Pelletier J, Topisirovic I (2015) Targeting the translation machinery in cancer. Nat Rev Drug Discov 14:261-278

Biedenkopf N, Lange-Grünweller K, Schulte FW, Weißer A, Müller C, Becker D, Becker S, Hartmann RK, Grünweller A (2017) The natural compound silvestrol is a potent inhibitor of Ebola virus replication. Antiviral Res 137:76-81

Bleumink M, Köhler R, Giaisi M, Proksch P, Krammer PH, LiWeber M (2011) Rocaglamide breaks TRAIL resistance in HTLV-1-associated adult T-cell leukemia/lymphoma by translational suppression of c-FLIP expression. Cell Death Differ 18:362-370

Blum L, Geisslinger G, Parnham MJ, Grünweller A, Schiffmann S (2020) Natural antiviral compound silvestrol modulates human monocyte-derived macrophages and dendritic cells. J Cell Mol Med 00:1-12

Bohnenstengel FI, Steube KG, Meyer C, Nugroho BW, Hung PD, Kiet LC, Proksch P (1999a) Structure activity relationships of antiproliferative rocaglamide derivatives from Aglaia species (Meliaceae). Z Naturforsch 54:55-60

Bohnenstengel FI, Steube KG, Meyer C, Quentmeier H, Nugroho BW, Proksch P (1999b) $1 H$-Cyclopenta[ $b$ ]benzofuran lignans from Aglaia species inhibit cellproliferation and alter cell cycle distribution in human monocytic leukemia cell lines. Z Naturforsch 54:1075-1083

Bordeleau ME, Robert F, Gerard B, Lindqvist L, Chen SMH, Wendel HG, Brem B, Greger H, Lowe SW, Porco JA Jr, Pelletier J (2008) Therapeutic suppression of translation initiation modulates chemosensitivity in a mouse lymphoma model. J Clin Invest 118:2651-2660

Brader G, Vajrodaya S, Greger H, Bacher M, Kalchhauser H, Hofer O (1998) Bisamides, lignans, triterpenes, and insecticidal cyclopenta[b]benzofurans from Aglaia species. J Nat Prod 61:1482-1490

Brem B (2002) Distribution and insecticidal properties of characteristic plant constituentsfrom tropical Aglaia and Stemona species. Ph.D thesis, University of Vienna

Bringmann G, Mühlbacher J, Messer K, Dreyer M, Ebel R, Nugroho BW, Wray V, Proksch P (2003) Cyclorocaglamide, the first bridged cyclopentatetrahydrobenzofuran, and a related "open chain" rocaglamide derivative from Aglaia oligophylla. J Nat Prod 66:80-85

Callahan KP, Minhajuddin M, Corbett C, Lagadinou ED, Rossi RM, Grose V, Balys MM, Pan L, Jacob S, Frontier A, Grever MR, Lucas DM, Kinghorn AD, Liesveld JL, Becker MW, Jordan CT (2014) Flavaglines target primitive leukemia cells and enhance anti-leukemia drug activity. Leukemia 1-9

Cencic R, Carrier M, Galicia-Vázquez G, Bordeleau ME, Sukarieh R, Bourdeau A, Brem B, Teodoro JG, Greger H, Tremblay ML, Porco JA Jr, Pelletier J (2009) Antitumor activity and mechanism of action of the cyclopenta[$[b]$ benzofuran, silvestrol. PLoS ONE 4:e5223

Cencic R, Carrier M, Trnkus A, Porco JA Jr, Minden M, Pelletier J (2010) Synergistic effects of inhibiting translation initiation in combination with cytotoxic agents in acute myelogenous leukemia cells. Leuk Res 34:535-541 
Chaidir HJ, Nugroho BW, Bohnenstengel FI, Wray V, Witte L, Hung PD, Kiet LC, Sumaryono W, Proksch P (1999) New insecticidal rocaglamide derivatives from flowers of Aglaia dupperiana (Meliaceae). Phytochemistry 52:837-842

Chaidir LWH, Ebel R, Edrada RA, Wray V, Nimtz M, Sumaryono W, Proksch P (2001) Rocaglamides, glycosides, and putrescine bisamides from Aglaia dasyclada. J Nat Prod 64:1216-1220

Chambers JM, Lindqvist LM, Webb A, Huang DCS, Savage GP, Rizzacasa MA (2013) Synthesis of biotinylated episilvestrol: highly selective targeting of the translation factors eIFAI/II. Org Lett 15:1406-1409

Chambers JM, Lindqvist LM, Savage GP, Rizzacasa MA (2016) Total synthesis of a biotinylated rocaglate: selective targeting of the translation factors eIF4AI/II. Bioorg Med Chem Lett 26:262-264

Chan K, Robert F, Oertlin C, Kapeller-Libermann D, Avizonis D, Gutierrez J, Handly-Santana A, Doubrovin M, Park J, Schoepfer C, DaSilva B, Yao M, Gorton F, Shi J, Thomas CJ, Brown LE, Porco JA Jr, Pollak M, Larsson O, Pelletier J, Chio IIC (2019) eIF4A supports an oncogenic translation program in pancreatic ductal adenocarcinoma. Nat Commun 10:5151

Chen WL, Pan L, Kinghorn AD, Swanson SM, Burdette JE (2016) Silvestrol induces early autophagy and apoptosis in human melanoma cells. BMC Cancer 16:17

Chen M, Asanuma M, Takahashi M, Shichino Y, Mito M, Fujiwara K, Saito H, Floor SN, Ingolia NT, Sodeoka M, Dodo K, Ito T, Iwasaki S (2021) Dual targeting of DDX3 and eIF4A by the translation inhibitor rocaglamide A. Cell Chem Biol 28:1-12

Chin YW, Chae HS, Lee J, Bach TT, Ahn KS, Lee HK, Joung H, Oh SR (2010) Bisamides from the twigs of Aglaia perviridis collected in Vietnam. Bull Korean Chem Soc 31:2665-2667

Chu J, Pelletier J (2015) Targeting the eIF4A RNA helicase as an anti-neoplastic approach. Biochim Biophys Acta 1849:781-791

Chu J, Cencic R, Wang W, Porco JA Jr, Pelletier J (2016a) Translation inhibition by rocaglates is independent of eIF4E phosphorylation status. Mol Cancer Ther 15:136-141

Chu J, Galicia-Vázquez G, Cencic R, Mills JR, Katigbak A, Porco JA Jr, Pelletier J (2016b) CRISPR-mediated drugtarget validation reveals selective pharmacological inhibition of the RNA helicase, eIF4A. Cell Rep 15:2340-2347

Chu J, Zhang W, Cencic R, Devine WG, Beglov D, Henkel T, Brown LE, Vajda S, Porco JA Jr, Pelletier J (2019) Amidino-rocaglates: a potent class of eIF4A inhibitors. Cell Chem Biol 26:1586-1593

Chumkaew P, Kato S, Chantrapromma K (2006) Potent cytotoxic rocaglamide derivatives from the fruits of Amoora cucullata. Chem Pharm Bull 54:1344-1346

Cui BL, Chai HB, Santisuk T, Reutrakul V, Farnsworth NR, Cordell GA, Pezzuto JM, Kinghorn AD (1997) Novel cytotoxic $1 H$-cyclopenta[b]benzofuran lignans from Aglaia elliptica. Tetrahedron 53:17625-17632

Daker M, Yeo JT, Bakar N, Saiyidatina A, Rahman AA, Ahmad M, Yeo TC, Khoo ASB (2016) Inhibition of nasopharyngeal carcinoma cell proliferation and synergism of cisplatin with silvestrol and episilvestrol from Aglaia stellatopilosa. Exp Ther Med 11:2117-2126

Detterbeck R, Hesse M (2002) Synthesis and structure elucidation of open-chained putrescine-bisamides from Aglaia species. Tetrahedron 58:6887-6893

Dobler MR, Bruce I, Cederbaum F, Cooke NG, Diorazio LJ, Hall RG, Irving E (2001) Total synthesis of ( \pm )-rocaglamide and some aryl analogues. Tetrahedron Lett 42:8281-8284

Dreyer M, Nugroho BW, Bohnenstengel FI, Ebel R, Wray V, Witte L, Bringmann G, Mühlbacher J, Herold M, Hung PD, Kiet LC, Proksch P (2001) New insecticidal rocaglamide derivatives and related compounds from Aglaia oligophylla. J Nat Prod 64:415-420

Drinić M, Raninger A, Zraunig A, Astelbauer F, Leitsch D, Obwaller A, Walochnik J, Greger H, Duchene M (2019) Activity of methylgerambullin from Glycosmis species (Rutaceae) against Entamoeba histolytica and Giardia duodenalis in vitro. Int $\mathbf{J}$ Parasitol Drugs Drug Resist 10:109-117

Duh CY, Wang SK, Hou RS, Wu YC, Wang Y, Cheng MC, Chang TT (1993) Dehydroodorin, a cytotoxic diamide from the leaves of Aglaia formosana. Phytochemistry 34:857-858

Dumontet V, Thoison O, Omobuwajo OR, Martin MT, Perromat G, Chiaroni A, Riche C, Pais M, Sévenet T (1996) New nitrogenous and aromatic derivatives from Aglaia argentea and A. forbesii. Tetrahedron 52:6931-6942

Duong NT (2005) Isolation and structure elucidation of insecticidal secondary metabolites from Aglaia species collected in Vietnam. $\mathrm{PhD}$ thesis, University of Düsseldorf, Germany

Duong TN, Edrada RA, Ebel R, Wray V, Frank W, Duong AT, Lin WH, Proksch P (2007) Putrescine bisamides from Aglaia gigantea. J Nat Prod 70:1640-1643

Duong NT, Edrada-Ebel RA, Ebel R, Lin WH, Duong AT, Dang XQ, Nguyen NH, Proksch P (2014) New rocaglamide derivatives from Vietnam Aglaia species. Nat Prod Commun 9:833-834

Ebada SS, Lajkiewicz N, Porco JA Jr, Li-Weber M, Proksch P (2011) Chemistry and biology of rocaglamides (= flavaglines) and related derivatives from Aglaia species (Meliaceae). Prog Chem Org Nat Prod 94:1-58

Elgner F, Sabino C, Basic M, Ploen D, Grünweller A, Hildt E (2018) Inhibition of Zika virus replication by silvestrol. Viruses 10:149

Emhemmed F, Azouaou SA, Hassan S, Lefevbre R, Désaubry L, Muller CD, Fuhrmann G (2019) The synthetic flavagline FL3 spares normal human skin cells from its cytotoxic effect via an activation of Bad. Toxicol in Vitro 60:27-35

Engelmeier D, Hadacek F, Pacher T, Vajrodaya S, Greger H (2000) Cyclopenta[b]benzofurans from Aglaia species with pronounced antifungal activity against rice blast fungus (Pyricularia grisea). J Agric Food Chem 48:1400-1404

Ernst JT, Thompson PA, Nilewski C, Sprengeler PA, Sperry S, Packard G, Michels T, Xiang A, Tran C, Wegerski CJ, Eam B, Young NP, Fish S, Chen J, Howard H, Staunton J, Molter J, Clarine J, Nevarez A, Chiang GG, Appleman JR, Webster KR, Reich SH (2020) Design of development candidate eFT226, a first in class inhibitor of eukaryotic 
initiation factor 4A RNA helicase. J Med Chem 63:5879-5955

Ewete F, Nicol RW, Hengsawad V, Sukumalanand P, Satasook C, Wiriyachitra P, Isman MB, Kahn Y, Duval F, Philogéne BJR, Arnason JT (1996) Insecticidal activity of Aglaia odorata extract and the active principle, rocaglamide, to the European corn borer, Ostrinia nubilalis (Hübn. (Lep., Pyralidae). J Appl Ent 120:483-488

Fahrig T, Gerlach I, Horváth E (2005) A synthetic derivative of the natural product rocaglaol is a potent inhibitor of cytokine-mediated signaling and shows neuroprotective activity in vitro and in animal models of Parkinson's disease and traumatic brain injury. Mol Pharmacol 67:1544-1555

Fuzzati N, Dyatmiko W, Rahman A, Achmad F, Hostettmann K (1996) Triterpenoids, lignans and a benzofuran derivative from the bark of Aglaia elaeagnoidea. Phytochemistry 42:1395-1398

Gerard B, Jones G II, Porco JA Jr (2004) A biomimetic approach to the rocaglamides employing photogeneration of oxidopyryliums derived from 3-hydroxyflavones. J Am Chem Soc 126:13620-13621

Glitscher M, Himmelsbach K, Woytinek K, Johne R, Reuter A, Spiric J, Schwaben L, Grünweller A, Hildt E (2018) Inhibition of hepatitis $\mathrm{E}$ spread by the natural compound silvestrol. Viruses 10:301

Greger H, Pacher T, Vajrodaya S, Bacher M, Hofer O (2000) Infraspecific variation of sulfur-containing bisamides from Aglaia leptantha. J Nat Prod 63:616-620

Greger H, Pacher T, Brem B, Bacher M, Hofer O (2001) Insecticidal flavaglines and other compounds from Fijian Aglaia species. Phytochemistry 57:57-64

Greger H, Hofer M, Teichmann K, Schinnerl J, Pannell CM, Vajrodaya S, Hofer O (2008) Amide-esters from Aglaia tenuicaulis - first representatives of a new class of compounds structurally related to bisamides and flavaglines. Phytochemistry 69:928-938

Gupta SV, Sass EJ, Davis ME, Edwards RB, Lozanski G, Heerema NA, Lehman A, Zhang X, Jarjoura D, Byrd JC, Pan L, Chan KK, Kinghorn AD, Phelps MA, Grever MR, Lucas DM (2011) Resistance to the translation initiation inhibitor silvestrol is mediated by $A B C B 1 / \mathrm{P}$-glycoprotein overexpression in acute lymphoblastic leukemia cells. AAPS J 13:357-364

Güssregen B, Fuhr M, Nugroho BW, Wray V, Witte L, Proksch $P$ (1997) New insecticidal rocaglamide derivatives from flowers of Aglaia odorata. Z Naturforsch 52:339-344

Hall RG, Bruce I, Cooke NG, Diorazio LJ, Cederbaum F, Dobler MR, Irving E (2017) Investigating the structure-activity relationship of the insecticidal natural product rocaglamide. Chimia 71:845-850

Hao P, Yu J, Ward R, Liu Y, Hao Q, An S, Xu T (2020) Eukaryotic translation initiation factors as promising targets in cancer therapy. Cell Commun Sign 18:175

Harmouch E, Seitlinger J, Chaddad H, Ubeaud-Sequier G, Barths J, Saidu S, Désaubry L, Grandemange S, Massfelder T, Fuhrmann G, Fioretti F, Dontenwill M, Benkirane-Jessel N, Idoux-Gillet Y (2020) Flavagline synthetic derivative induces senescence in glioblastoma cancer cells without being toxic to healthy astrocytes. Sci Rep 10:13750

Harneti D, Supratman U (2021) Phytochemistry and biological activities of Aglaia species. Phytochemistry 181:112540
Hausott B, Greger H, Marian B (2004) Flavaglines: a group of efficient growth inhibitors block cell cycle progression and induce apoptosis in colorectal cancer cells. Int J Cancer 109:933-940

Hawkins BC, Lindqvist LM, Nhu D, Sharp PP, Segal D, Powell AK, Campbell M, Ryan E, Chambers JM, White JM, Rizzacasa MA, Lessene G, Huang DCS, Burns CJ (2014) Simplified silvestrol analogues with potent cytotoxic activity. Chem Med Chem 9:1556-1566

Hayashi N, Lee KH, Hall IH, McPhail AT, Huang HC (1982) Structure and stereochemistry of (-)-odorinol, an antileukemic diamide from Aglaia odorata. Phytochemistry 21:2371-2373

Henss L, Scholz T, Grünweller A, Schnierle BS (2018) Silvestrol inhibits Chikungunya virus replication. Viruses 10:592

Hiort J, Chaidir BFI, Nugroho BW, Schneider C, Wray V, Witte L, Hung PD, Kiet LC, Proksch P (1999) New insecticidal rocaglamide derivatives from the roots of Aglaia duperreana. J Nat Prod 62:1632-1635

Hofer M (2002) Infraspecific chemical variation within Aglaia elaeagnoidea (Meliaceae) from SE-Asia and Australia. Master-thesis, University of Vienna

Hwang BY, Su BN, Chai H, Mi Q, Kardono LBS, Afriastini JJ, Riswan S, Santarsiero BD, Mesecar AD, Wild R, Fairchild CR, Vite GD, Rose WC, Farnsworth NR, Cordell GA, Pezzuto JM, Swanson SM, Kinghorn AD (2004) Silvestrol and Episilvestrol, potential anticancer rocaglate derivatives from Aglaia silvestris. J Org Chem 69:3350-3358

Inada A, Shono K, Murata H, Inatomi Y, Darnaedi D, Nakanishi $\mathrm{T}$ (2000) Three putrescine bisamides from the leaves of Aglaia grandis. Phytochemistry 53:1091-1095

Inada A, Nishino H, Kuchide M, Takayasu J, Mukainaka T, Nobukuni Y, Okuda M, Tokuda H (2001a) Cancer chemopreventive activity of odorine and odorinol from Aglaia odorata. Biol Pharm Bull 24:1282-1285

Inada A, Sorano T, Murata H, Inatomi Y, Darnaedi D, Nakanishi $\mathrm{T}$ (2001b) Diamide derivatives and cycloartanes from the leaves of Aglaia elliptica. Chem Pharm Bull 49:1226-1228

Ishibashi F, Satasook C, Isman MB, Towers GHN (1993) Insecticidal $1 H$-cyclopentatetrahydro[b]benzofurans from Aglaia odorata. Phytochemistry 32:307-310

Iwasaki S, Floor SN, Ingolia NT (2016) Rocaglates convert DEAD-box protein eIF4A into a sequence-selective translational repressor. Nature 534:558-561

Iwasaki S, Iwasaki W, Takahashi M, Sakamoto A, Watanabe C, Shichino Y, Floor SN, Fujiwara K, Mito M, Dodo K, Sodeoka M, Imataka H, Honma T, Fukuzawa K, Ito T, Ingolia NT (2019) The translation inhibitor rocaglamide targets a bimolecular cavity between eIF4A and polypurine RNA. Mol Cell 73:738-748

Iyer KR, Whitesell L, Porco JA Jr, Henkel T, Brown LE, Robbins N, Cowen LE (2020) Translation inhibition by rocaglates activates a species-specific cell death program in the emerging fungal pathogen Candida auris. Mbio 11:e03329-e3419

Janprasert J, Satasook C, Sukumalanand P, Champagne DE, Isman MB, Wiriyachitra P, Towers GHN (1993) Rocaglamide, a natural benzofuran insecticide from Aglaia odorata. Phytochemistry 32:67-69 
Joycharat N, Greger H, Hofer O, Saifah E (2008a) Flavaglines and triterpenoids from the leaves of Aglaia forbesii. Phytochemistry 69:206-211

Joycharat N, Greger H, Hofer O, Saifah E (2008b) Flavaglines and triterpenes as chemical markers of Aglaia oligophylla. Biochem Syst Ecol 36:584-587

Khewkhom N, Greger H, Sangchote S (2006) Antifungal activity of flavaglines from Aglaia species. Agricult Sci J 37:66-71

Kim S, Su BN, Riswan S, Kardono LBS, Afriastini JJ, Gallucci JC, Chai H, Farnsworth NR, Cordell GA, Swanson SM, Kinghorn AD (2005) Edulisones A and B, two epimeric benzo $[b]$ oxepine derivatives from the bark of Aglaia edulis. Tetrahedron Lett 46:9021-9024

Kim S, Chin YW, Su BN, Riswan S, Kardono LBS, Afriastini JJ, Chai H, Farnsworth NR, Cordell GA, Swanson SM, Kinghorn AD (2006a) Cytotoxic flavaglines and bisamides from Aglaia edulis. J Nat Prod 69:1769-1775

Kim S, Salim AA, Swanson SM, Kinghorn AD (2006b) Potential of cyclopenta[b]benzofurans from Aglaia species in cancer chemotherapy. Anticancer Agents Med Chem 6:319-345

Kim S, Hwang BY, Su BN, Chai H, Mi Q, Kinghorn AD, Wild R, Swanson SM (2007) Silvestrol, a potential anticancer rocaglate derivative from Aglaia foveolata, induces apoptosis in LNCaP cells through the mitochondrial/apoptosome pathway without activation of executioner caspase-3 or -7. Anticanc Res 27:2175-2184

King ML, Chiang CC, Ling HC, Fujita E, Ochiai M, McPhail AT (1982) X-ray crystal structure of rocaglamide, a novel antileukemic $1 H$-cyclopenta[b]benzofuran from Aglaia elliptifolia. J Chem Soc Chem Commun 1150-1151

Ko FN, Wu TS, Liou MJ, Huang TF, Teng CM (1992) PAF antagonism in vitro and in vivo by aglafoline from Aglaia elliptifolia Merr. Eur J Pharmacol 218:129-135

Kogure T, Kinghorn AD, Yan I, Bolon B, Lucas DM, Grever MR, Patel T (2013) Therapeutic potential of the translation inhibitor silvestrol in hepatocellular cancer. PLoS ONE 8:e76136

Kokpol U, Venaskulchai B, Simpson J, Weavers RT (1994) Isolation and X-ray structure determination of a novel pyrimidinone from Aglaia odorata. J Chem Soc Chem Commun 773-774

Koul O, Kaur H, Goomber S, Wahab S (2004) Bioefficacy and mode of action of rocaglamide from Aglaia elaeagnoidea (syn. A. roxburghiana) against gram pod borer, Helicoverpa armigera (Hübner). J Appl Ent 128:177-181

Koul O, Singh G, Singh R, Multani JS (2005) Bioefficacy and mode-of-action of aglaroxin A from Aglaia elaeagnoidea (syn. A. roxburghiana) against Helicoverpa armigera and Spodoptera litura. Entomol Exp Appl 114:197-204

Lajkiewicz NJ, Roche SP, Gerard B, Porco JA Jr (2012) Enantioselective photocycloaddition of 3-hydroxyflavones: total syntheses and absolute configuration assignments of (+)-ponapensin and (+)-elliptifoline. J Am Chem Soc 134:13108-13113

Langlais D, Cencic R, Moradin N, Kennedy JM, Ayi K, Brown LE, Crandall I, Tarry MJ, Schmeing M, Kain KC, Porco JA Jr, Pelletier J, Gros P (2018) Rocaglates as dual-targeting agents for experimental cerebral malaria. PNAS 115:E2366-E2375
Lee SK, Cui B, Mehta RR, Kinghorn AD, Pezzuto JM (1998) Cytostatic mechanism and antitumor potential of novel $1 \mathrm{H}$ cyclopenta[b]benzofuran lignans isolated from Aglaia elliptica. Chem Biolog Interact 115:215-228

Li H, Fu B, Wang MA, Li N, Liu WJ, Xie ZQ, Ma YQ, Qin Z (2008) Total synthesis and biological activity of $( \pm$ )rocaglamide and its 2,3-di-epi analogue. Eur J Org Chem $1753-1758$

Liu B, Xu YK (2016) Cytotoxicity and synergistic effect of the constituents from roots of Aglaia odorata (Meliaceae). Nat Prod Res 30:433-437

Liu T, Nair SJ, Lescarbeau A, Belani J, Peluso S, Conley J, Tillotson B, O'Hearn P, Smith S, Slocum K, West K, Helble J, Douglas M, Bahadoor A, Ali J, McGovern K, Fritz C, Palombella VJ, Wylie A, Castro AC, Tremblay MR (2012) Synthetic silvestrol analogues as potent and selective protein synthesis inhibitors. J Med Chem 55:8859-8878

Liu S, Wang H, Zuo WJ, Zhao YX, Li XN, Mei WL, Dai HF (2013) Two new rocaglamide derivatives from twigs of Aglaia odorata var. microphyllina. Phytochem Lett 6:5-8

Li-Weber M (2015) Molecular mechanisms and anti-cancer aspects of the medicinal phytochemicals rocaglamides (= flavaglines). Int J Cancer 137:1791-1799

Lucas DM, Edwards RB, Lozanski G, West DA, Shin JD, Vargo MA, Davis ME, Rozewski DM, Johnson AJ, Su BN, Goettl VM, Heerema NA, Lin TS, Lehman A, Zhang X, Jarjoura D, Newman DJ, Byrd JC, Kinghorn AD, Grever MR (2009) The novel plant-derived agent silvestrol has B-cell selective activity in chronic lymphocytic leukemia and acute lymphoblastic leukemia in vitro and in vivo. Blood 113:4656-4666

Lucas DM, Still PC, Bueno Pérez L, Grever MR, Kinghorn AD (2010) Potential of plant-derived natural products in the treatment of leukemia and lymphoma. Curr Drug Targets 11:812-822

Maïga RI, Cencic R, Chu J, Waller DD, Brown LE, Devine WG, Zhang W, Sebag M, Porco JA Jr, Pelletier J (2019) Oxoaglaiastatin-mediated inhibition of translation initiation. Sci Rep 9:1265

Meurer-Grimes BM, Yu J, Vairo GL (2004) Therapeutic compounds and methods. U.S. Patent 6,710,075 B2, March 23

Mi Q, Su BN, Chai HB, Cordell GA, Farnsworth NR, Kinghorn AD, Swanson SM (2006a) Rocaglaol induces apoptosis and cell cycle arrest in $\mathrm{LNCaP}$ cells. Anticancer Res 26:947-952

Mi Q, Kim S, Hwang BY, Su BN, Chai HB, Arbiewa ZH, Kinghorn AD, Swanson SM (2006b) Silvestrol regulates $\mathrm{G}_{2} / \mathrm{M}$ checkpoint genes independent of p53 activity. Anticancer Res 26:3349-3356

Molleyres LP, Rindlisbacher A, Winkler T, Kumar V (1999) Insecticidal natural products: new rocaglamide derivatives from Aglaia roxburghiana. Pestic Sci 55:494-497

Muellner AN, Samuel R, Chase MW, Pannell CM, Greger H (2005) Aglaia (Meliaceae): an evaluation of taxonomic concepts based on DNA and secondary metabolites. Am J Bot 92:534-543

Muellner AN, Greger H, Pannell CM (2009) Genetic diversity and geographic structure in Aglaia elaeagnoidea (Meliaceae, Sapindales), a morphologically complex tree 
species, near the two extremes of its distribution. Blumea 54:207-216

Mulholland DA, Naidoo N (1998) A revision of the structure of ferrugin from Aglaia ferruginaea. Phytochemistry 470:1163

Müller C, Schulte FW, Lange-Grünweller K, Obermann W, Madhugiri R, Pleschka S, Ziebuhr J, Hartmann RK, Grünweller A (2018) Broadspectrum antiviral activity of the eIF4A inhibitor silvestrol against corona- and picornaviruses. Antivir Res 150:123-129

Müller C, Obermann W, Schulte FW, Lange-Grünweller K, Oestereich L, Elgner F, Glitscher M, Hildt E, Singh K, Wendel HG, Hartmann RK, Ziebuhr J, Grünweller A (2020) Comparison of broad-spectrum antiviral activities of the synthetic rocaglate CR-31-B(-) and the eIF4A-inhibitor silvestrol. Antivir Res 175:104706

Müller C, Obermann W, Karl N, Wendel HG, TaroncherOldenburg G, Pleschka S, Hartmann RK, Grünweller A, Ziebuhr J (2021) The rocaglate CR-31-B (-) inhibits SARS$\mathrm{CoV}-2$ replication at non-cytotoxic, low nanomolar concentrations in vitro and ex vivo. Antivir Res 186:105012

Nugroho BW, Edrada RA, Güssregen B, Wray V, Witte L, Proksch P (1997a) Insecticidal rocaglamide derivatives from Aglaia dupperiana. Phytochemistry 44:1455-1461

Nugroho BW, Güssregen B, Wray V, Witte L, Bringmann G, Proksch P (1997b) Insecticidal rocaglamide derivatives from Aglaia elliptica and A. harmsiana. Phytochemistry 45:1579-1585

Nugroho BW, Edrada RA, Wray V, Witte L, Bringmann G, Gehling M, Proksch P (1999) An insecticidal rocaglamide derivative and related compounds from Aglaia odorata (Meliaceae). Phytochemistry 51:367-376

Ohse T, Ohba S, Yamamoto T, Koyano T, Umezawa K (1996) Cyclopentabenzofuran lignan protein synthesis inhibitors from Aglaia odorata. J Nat Prod 59:650-652

Othman N, Pan L, Mejin M, Voong JCL, Chai HB, Pannell CM, Kinghorn AD, Yeo TC (2016) Cyclopenta[b]benzofuran and secodammarane derivatives from the stems of Aglaia stellatopilosa. J Nat Prod 79:784-791

Pan L, Kardono LBS, Riswan S, Chai H, Carache de Blanco EJ, Pannell CM, Soejarto DD, McCloud TG, Newman DJ, Kinghorn AD (2010) Isolation and characterization of minor analogues of silvestrol and other constituents from a large-scale re-collection of Aglaia foveolata. J Nat Prod 73:1873-1878

Pan L, Muñoz Acuña U, Li J, Jena N, Ninh TN, Pannell CM, Chai H, Fuchs JR, Carcache de Blanco EJ, Soejarto DD, Kinghorn AD (2013) Bioactive flavaglines and other constituents isolated from Aglaia perviridis. J Nat Prod 76:394-404

Pan L, Woodard JL, Lucas DM, Fuchs JR, Kinghorn AD (2014) Rocaglamide, silvestrol and structurally related bioactive compounds from Aglaia species. Nat Prod Rep 31:924-939

Pannell CM (1992) A taxonomic monograph of the genus Aglaia Lour. (Meliaceae). Kew Bulletin Additional Series XVI. Royal Botanic Gardens, Kew, London

Pannell CM (1994) Three new species, two new subspecies and five new combinations at the subspecific level in Aglaia Lour. (Meliaceae). Kew Bull 59:87-94

Patton JT, Lustberg ME, Lozanski G, Garman SL, Towns WH, Drohan CM, Lehman A, Zhang X, Bolon B, Pan L,
Kinghorn AD, Grever MR, Lucas DM, Baiocchi RA (2014) The translation inhibitor silvestrol exhibits direct anti-tumor activity while preserving innate and adaptive immunity against EBV-driven lymphoproliferative disease. Oncotarget 6:2693-2708

Pelletier J, Graff J, Ruggero D, Sonenberg N (2015) Targeting the eIF4F translation initiation complex: a critical nexus for cancer development. Cancer Res 75:250-263

Phongmaykin J, Kumamoto T, Ishikawa T, Saifah E, Suttisri R (2011) Biologically active constituents of Aglaia erythrosperma. Nat Prod Res 25:1621-1628

Polier G, Neumann J, Thuaud F, Ribeiro N, Gelhaus C, Schmidt HG, Giaisi M, Köhlen R, Müller WW, Proksch P, Leippe M, Janssen O, Désaubry L, Krammer PH, Li-Weber M (2012) The natural anticancer compounds rocaglamides inhibit the Raf-MEK-ERK pathway by targeting prohibin 1 and 2. Chem Biol 19:1093-1104

Proksch P, Edrada RA, Ebel R, Bohnenstengel FI, Nugroho BW (2001) Chemistry and biological activity of rocaglamide derivatives and related compounds in Aglaia species (Meliaceae). Curr Org Chem 5:923-938

Proksch P, Giaisi M, Treiber MK, Palfi K, Merling A, Spring H, Krammer PH, Li-Weber M (2005) Rocaglamide derivatives are immunosuppressive phytochemicals that target NF-AT activity in T cells. J Immunol 174:7075-7084

Puripattanavong J, Weber S, Brecht V, Frahm AW (2000) Phytochemical investigation of Aglaia andamanica. Planta Med 66:740-745

Purushothaman KK, Sarada A, Connolly JD, Akinniyi JA (1979) The structure of roxburghilin, a bis-amide of 2-aminopyrrolidine from the leaves of Aglaia roxburghiana (Meliaceae). J Chem Soc Perkin Trans I:3171-3174

Ribeiro N, Thuaud F, Nebigil C, Désaubry L (2012) Recent advances in the biology and chemistry of the flavaglines. Bioorg Med Chem 20:1857-1864

Rivero-Cruz JF, Chai HB, Kardono LBS, Setyowati FM, Afriatini JJ, Riswan S, Farnsworth NR, Cordell GA, Pezzuto JM, Swanson SM, Kinghorn AD (2004) Cytotoxic constituents of the twigs and leaves of Aglaia rubiginosa. J Nat Prod 67:343-347

Roche SP, Cencic R, Pelletier J, Porco JA Jr (2010) Biomimetic photocycloaddition of 3-hydroxyflavones: synthesis and evaluation of rocaglate derivatives as inhibitors of eukaryotic translation. Angew Chem Int Ed 49:6533-6538

Rodrigo CM, Cencic R, Roche SP, Pelletier J, Porco JA Jr (2012) Synthesis of rocaglamide hydroxamates and related compounds as eukaryotic translation inhibitors: synthetic and biological studies. J Med Chem 55:558-562

Sadlish H, Galicia-Vazquez G, Paris CG, Aust T, Bhullar B, Chang L, Helliwell SB, Hoepfner D, Knapp B, Riedl R, Roggo S, Schuierer S, Studer C, Porco JA Jr, Pelletier J, Movva NR (2013) Evidence for a functionally relevant rocaglamide binding site on the eIF4A-RNA complex. ACS Chem Biol 8:1519-1527

Saifah E, Jongbunprasert V, Kelley CJ (1988) Piriferine, a new pyrrolidine alkaloid from Aglaia pirifera leaves. J Nat Prod 51:80-82

Saifah E, Puripattanavong J, Likhitwitayawuid K, Cordell GA, Chai H, Pezzuto JM (1993) Bisamides from Aglaia species: structure analysis and potential to reverse drug resistance with cultured cells. J Nat Prod 56:473-477 
Saifah E, Suttisri R, Shamsub S, Pengsuparp T, Lipipun V (1999) Bisamides from Aglaia edulis. Phytochemistry 52:1085-1088

Salim AA, Chai HB, Rachman I, Riswan S, Kardono LBS, Farnsworth NR, Carcache-Blanco EJ, Kinghorn AD (2007a) Constituents of the leaves and stem bark of Aglaia foveolata. Tetrahedron 63:7926-7934

Salim AA, Pawlus AD, Chai HB, Farnsworth NR, Kinghorn AD, Carcache-Blanco EJ (2007b) Ponapensin, a cyclopenta $[b c]$ benzopyran with potent NF- $\kappa \mathrm{B}$ inhibitory activity from Aglaia ponapensis. Bioorg Med Chem Lett 17:109-112

Santagata S, Mendillo ML, Tang YC, Subramanian A, Perley CC, Roche SP, Wong B, Narayan R, Kwon H, Koeva M, Amon A, Golub TR, Porco JA Jr, Whitesell L, Lindquist S (2013) Tight coordination of protein translation and HSF1 activation supports the anabolic malignant state. Science 341(6143): 1238303

Saradhi UVRV, Gupta SV, Chiu M, Wang J, Ling Y, Liu Z, Newman DJ, Covey JM, Kinghorn AD, Marcucci G, Lucas DM, Grever MR, Phelps MA, Chan KK (2011) Characterization of silvestrol pharmacokinetics in mice using liquid chromatography-tandem mass spectrometry. AAPS J 13:347-356

Satasook C, Isman MB, Wiriyachitra P (1992) Activity of rocaglamide, an insecticidal natural product, against the variegated cutworm, Peridroma saucia (Lepidoptera: Noctuidae). Pestic Sci 36:53-58

Schatz JH, Oricchio E, Wolfe AL, Jiang M, Linkov I, Maragulia J, Shi W, Zhang Z, Rajasekhar VK, Pagano NC, Porco JA Jr, Teruya-Feldstein J, Rosen N, Zelenetz AD, Pelletier J, Wendel HG (2011) Targeting cap-dependent translation blocks converging survival signals by AKT and PIM kinases in lymphoma. J Exp Med 208:1799-1807

Schneider C, Bohnenstengel FI, Nugroho BW, Wray V, Witte L, Hung PD, Kiet LC, Proksch P (2000) Insecticidal rocaglamide derivatives from Aglaia spectabilis (Meliaceae). Phytochemistry 54:731-736

Schulz G, Victoria C, Kirschning A, Steinmann E (2021) Rocaglamide and silvestrol: a long story from anti-tumor to anti-coronavirus compounds. Nat Prod Rep 38:18-23

Seger C, Hofer O, Greger H (2000) Corrected structure of aglalactone isolated from Aglaia elaeagnoidea (Meliaceae). Monats Chem 131:1161-1165

Seger C, Pacher T, Greger H, Saifah E, Hofer O (2002) Aglairubin: structure revision of a chemotaxonomically interesting bisamide in Aglaia (Meliaceae). Monatsh Chem 133:97-100

Shiengthong D, Ungphakorn A, Lewis DE, Massy-Westropp RA (1979) Constituents of Thai medicinal plants-IV. New nitrogenous compounds-odorine and odorinol. Tetrahedron Lett 2247-2250

Silvera D, Formenti SC, Schneider RJ (2010) Translational control in cancer. Nat Rev Cancer 10:254-266

Sridharan S, Robeson M, Bastihalli-Tukaramrao D, Howard CM, Subramaniyan B, Tilley AMC, Tiwari AK, Raman D (2019) Targeting of the eukaryotic translation initiation factor $4 \mathrm{~A}$ against breast cancer stemness. Front Oncol 9:1311

Su BN, Chai H, Mi Q, Riswan S, Kardono LBS, Afriastini JJ, Santarsiero BD, Mesecar AD, Farnsworth NR, Cordell GA,
Swanson SM, Kinghorn AD (2006) Activity-guided isolation of cytotoxic constituents from the bark of Aglaia crassinervia collected in Indonesia. Bioorg Med Chem 14:960-972

Taroncher-Oldenburg G, Müller C, Obermann W, Ziebuhr J, Hartmann RK, Grünweller A (2021) Targeting the DEADbox RNA helicase eIF4A with rocaglates-a pan-antiviral strategy for minimizing the impact of future RNA virus pandemics. Microorganisms 9:540

Taylor J, Yeomans AM, Packham G (2020) Targeted inhibition of mRNA translation initiation factors as a novel therapeutic strategy for mature B-cell neoplasms. Explor Target Antitumor Ther 1:3-25

Thede K, Diedrichs N, Ragot JP (2004) Stereoselective synthesis of $( \pm)$-rocaglaol analogues. Org Lett 6:4595-4597

Thuaud F, Bernard Y, Turkeri G, Dirr R, Aubert G, Cresteil T, Baguet A, Tomasetto C, Svitkin Y, Sonenberg N, Nebigil CG, Désaubry L (2009) Synthetic analogue of rocaglaol displays a potent and selective cytotoxicity in cancer cells: involvement of apoptosis inducing factor and caspase- 12 . J Med Chem 52:5176-5187

Thuaud F, Ribeiro N, Gaiddon C, Cresteil T, Désaubry L (2011) Novel flavaglines displaying improved cytotoxicity. J Med Chem 54:411-415

Thuaud F, Ribeiro N, Nebigil CG, Désaubry L (2013) Prohibitin ligands in cell death and survival: mode of action and therapeutic potential. Chem Biol 20:316-331

Todt D, Moeller N, Praditya D, Kinast V, Friesland M, Engelmann M, Verhoye L, Sayed IM, Behrendt P, Dao Thi VL, Meuleman P, Steinmann E (2018) The natural compound silvestrol inhibits hepatitis E virus (HEV) replication in vitro and in vivo. Antivir Res 157:151-158

Trost BM, Greenspan PD, Yang BV, Saulnier MG (1990) An unusual oxidative cyclization. A synthesis and absolute stereochemical assignment of (-)-rocaglamide. J Am Chem Soc 112:9022-9024

Wang SK, Duh CY (2001) Cytotoxic cyclopenta[b]benzofuran derivatives from the stem bark of Aglaia formosana. Planta Med 67:555-557

Wang SK, Cheng YJ, Duh CY (2001a) Cytotoxic constituents from leaves of Aglaia elliptifolia. J Nat Prod 64:92-94

Wang BG, Ebel R, Nugroho BW, Prijono D, Frank W, Steube KG, Hao XJ, Proksch P (2001b) Aglacins A-D, first representatives of a new class of aryltetralin cyclic ether lignans from Aglaia cordata. J Nat Prod 64:1521-1526

Wang BG, Ebel R, Wang CY, Wray V, Proksch P (2002) New methoxylated aryltetrahydronaphthalene lignans and a norlignan from Aglaia cordata. Tetrahedron Lett 43:5783-5787

Wang BG, Peng H, Huang HL, Li XM, Eck G, Gong X, Proksch $\mathrm{P}$ (2004a) Rocaglamide, aglain, and other related derivatives from Aglaia testicularis (Meliaceae). Biochem Syst Ecol 32:1223-1226

Wang BG, Ebel R, Wang CY, Edrada RA, Wray V, Proksch P (2004b) Aglacins I-K, three highly methoxylated lignans from Aglaia cordata. J Nat Prod 67:682-684

Webb TE, Davies M, Maher J, Sarker D (2020) The eIF4A inhibitor silvestrol sensitizes T-47D ductal breast carcinoma cells to external-beam radiotherapy. Clin Transl Rad Oncol 24:123-126 
Wu TS, Liou MJ, Kuoh CS, Teng CM, Nagao T, Lee KH (1997) Cytotoxic and antiplatelet aggregation principles from Aglaia elliptifolia. J Nat Prod 60:606-608

$\mathrm{Xu}$ YJ, Wu XH, Tan BKH, Lai YH, Vittal JJ, Imiyabir Z, Madani L, Khozirah KS, Goh SH (2000) Flavonol-cinnamate cycloadducts and diamide derivatives from Aglaia laxiflora. J Nat Prod 63:473-476

Yan C, Gong L, Chen L, Xu M, Abou-Hamdan H, Tang M, Désaubry L, Song Z (2020) PHB2 (prohibitin 2) promotes PINK1-PRKN/Parkin-dependent mitophagy by the PARLPGAM5-PINK1 axis. Autophagy 16:419-434

Yuan G, Chen X, Liu Z, Wei W, Shu Q, Abou-Hamdan H, Jiang L, Li X, Chen R, Désaubry L, Zhou F, Xie D (2018) Flavagline analog FL3 induces cell cycle arrest in urothelial carcinoma cell of the bladder by inhibiting the Akt/PHB interaction to activate the GADD $45 \alpha$ pathway. J Exp Clin Cancer Res 37:21

Zhang L, Zhang JH, Yang SM, Tan CH, Luo HF, Zhu DY (2010) Chemical constituents from the leaves of Aglaia perviridis. J Asian Nat Prod Res 12:215-219

Zhang L, Wang LH, Yang YF, Yang SM, Zhang JH, Tan CH (2011) Aglaianine, a new bisamide from Aglaia abbreviata. Nat Prod Res 25:1676-1679

Zhao Q, Abou-Hamdan H, Désaubry L (2016) Recent advances in the synthesis of flavaglines, a family of potent bioactive natural compounds originating from Traditional Chinese Medicine. Eur J Org Chem 5908-5916

Zhao Y, Li T, Tian S, Meng W, Sui Y, Yang J, Wang B, Liang Z, Zhao H, Han Y, Tang Y, Zhang L, Ma J (2020) Effctive inhibition of MYC-amplified group 3 medulloblastoma through targeting EIF4AI. Cancer Manag Res 12:12743-12485

Zhu JY, Lavrik IN, Mahlknecht U, Giaisi M, Proksch P, Krammer PH, Li-Weber M (2007) The traditional Chinese herbal compound rocaglamide preferentially induces apoptosis in leukemia cells by modulation of mitogen-activated protein kinase activities. Int $\mathrm{J}$ Cancer 121:1839-1846

Zhu JY, Giaisi M, Köhler R, Müller WW, Mühleisen A, Proksch P, Krammer PH, Li-Weber M (2009) Rocaglamide sensitizes leukemic $\mathrm{T}$ cells to activation-induced cell death by differential regulation of CD95L and c-FLIP expression. Cell Death Differ 16:1289-1299

Publisher's Note Springer Nature remains neutral with regard to jurisdictional claims in published maps and institutional affiliations. 